\title{
PHƯƠNG PHÁP NGHIÊN CỨU TRONG KINH DOANH
}

Ph.D. Đào Duy Tùng Khoa Quản trị Kinh doanh Đại học Tây Đô, Cần Thơ 


\title{
Chương 9
}

\author{
THIẾT KẾ BẢNG HỏI, \\ XÁC ĐịNH Cỡ MÃ̃U, \\ THANG ĐO ĐO LƯỜNG \& \\ PHƯơNG PHÁP CHỌN MẪU
}




\subsection{Ba phương pháp tiếp cận nghiên cứU}

5

Tiếp cận nghiên cứu

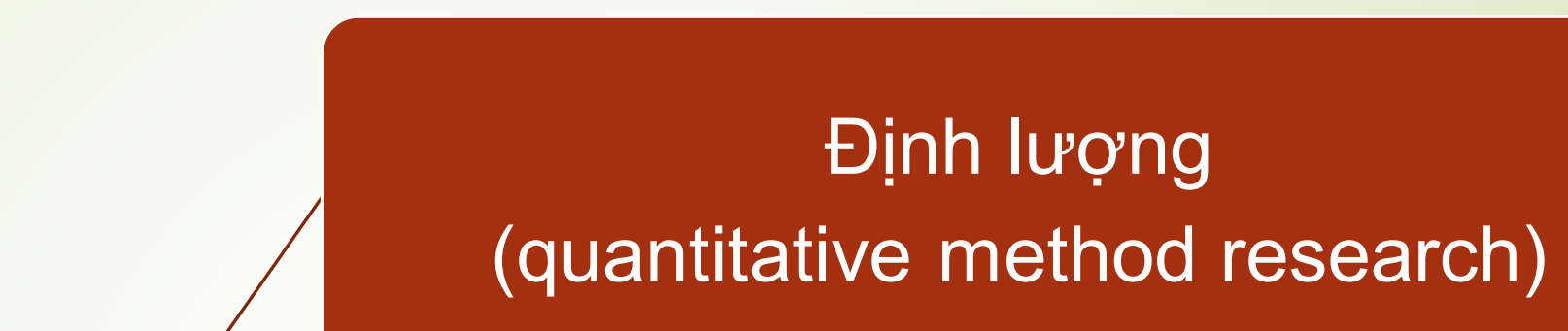

Hỗn hợp

(mixed-methods research) 


\subsection{Ba phương pháp tiếp cận nghiên cứu}

\section{Phương pháp thu thập dữ liệu}

- Thảo luận nhóm tập trung (focus group discussion);

- Phỏng vấn sâu (in-depth interview);

- Phông vấn chuyên gia (expert interview);

Nghiên cứu tình huống (case studies);

Lý thuyết nền (grounded theory);

Hình thức phỏng vấn \& thảo luận:

- có cấu trúc (structured interview)

- bán cấu trúc (semi-structured interview)

- không cấu trúc (unstructured interview)

- Dạng câu hỏi đóng (closed-ended questions)

- Dạng câu hỏi mở (open-ended questions) 


\subsection{Ba phương pháp tiếp cận nghiên cứU}

9.1.1 Nghiên cứu định tính (Qualitative methods research)

\section{Phương pháp xử lý và phân tích dữ liệu}

Sử dụng Nvivo để phân tích nội dung (content analysis), SPSS để phân tích dữ liệu quả đối với

- Các bản ghi chép kết quả phỏng vấn chuyên gia;

- Các bản ghi chép kết quả phỏng vấn tay đôi;

- Các bản ghi chép kết quả thảo luận nhóm chuyên sâu;

- Các bản ghi chép kết quả thảo luận nhóm tập trung;

- Các bản ghi âm, thu hình. 


\subsection{Ba phương pháp tiếp cận nghiên cứU}

\section{Phương pháp thu thập dũ liệu}

Phiếu điều tra (questionnaire, survey)

Thảo luận nhóm tập trung (focus group discussion)

Hình thức phỏng vấn \& thảo luận:

- có cấu trúc (structured interview)

- bán cấu trúc (semi-structured interview)

- không cấu trúc (unstructured interview)

- Dạng câu hỏi đóng (closed-ended questions)

- Dạng câu hỏi mở (open-ended questions) 


\subsection{Ba phương pháp tiếp cận nghiên cứU}

9.1.2 Nghiên cứu định lượng (Quantitative methods research)

Phương pháp xử lý và phân tích dữ liệu

Sử dụng SPSS để xử lý và phân tích dữ liệu đối với

- các phiếu điều tra 


\subsection{Ba phương pháp tiếp cận nghiên cứU}

\subsubsection{Nghiên cứu hỗn hợp (mixed-methods research)}

\section{Phương pháp thu thập dữ liệu}

- Phiếu câu hỏi khảo sát (questionnaire, survey)

- Thảo luận nhóm tập trung (focus group discussion)

- Phỏng vấn sâu (in-depth interview)

- Phỏng vấn chuyên gia (expert interview)

Hình thức phỏng vấn \& thảo luận:

- có cấu trúc (structured interview)

- bán cấu trúc (semi-structured interview)

- không cấu trúc (unstructured interview)

- Dạng câu hỏi đóng (closed-ended questions) 


\subsection{Phân loại dữ liệu và các phương pháp thu thập dữ liệu}

\section{1}

- Thu thập dữ liệu là một giai đoạn có ý nghĩa vô cùng quan trọng đối với quá trình nghiên cứu

- Tuy nhiên việc thu thập dữ liệu lại thường tốn nhiều thời gian, công sức và chi phí

- Do đó cần phải nắm chắc các phương pháp thu thập dữ liệu để từ đó chọn ra các phương pháp thích hợp với hiện tượng, làm cơ sở để lập kế hoạch thu thập dữ liệu một cách khoa học, nhằm để đạt được hiệu quả cao nhất của giai đoạn quan trọng này. 


\subsection{Phân loại thông tin và các phương pháp thu thập dữ liệu}

12 9.2.1 Nguồn thông tin nghiên cứu

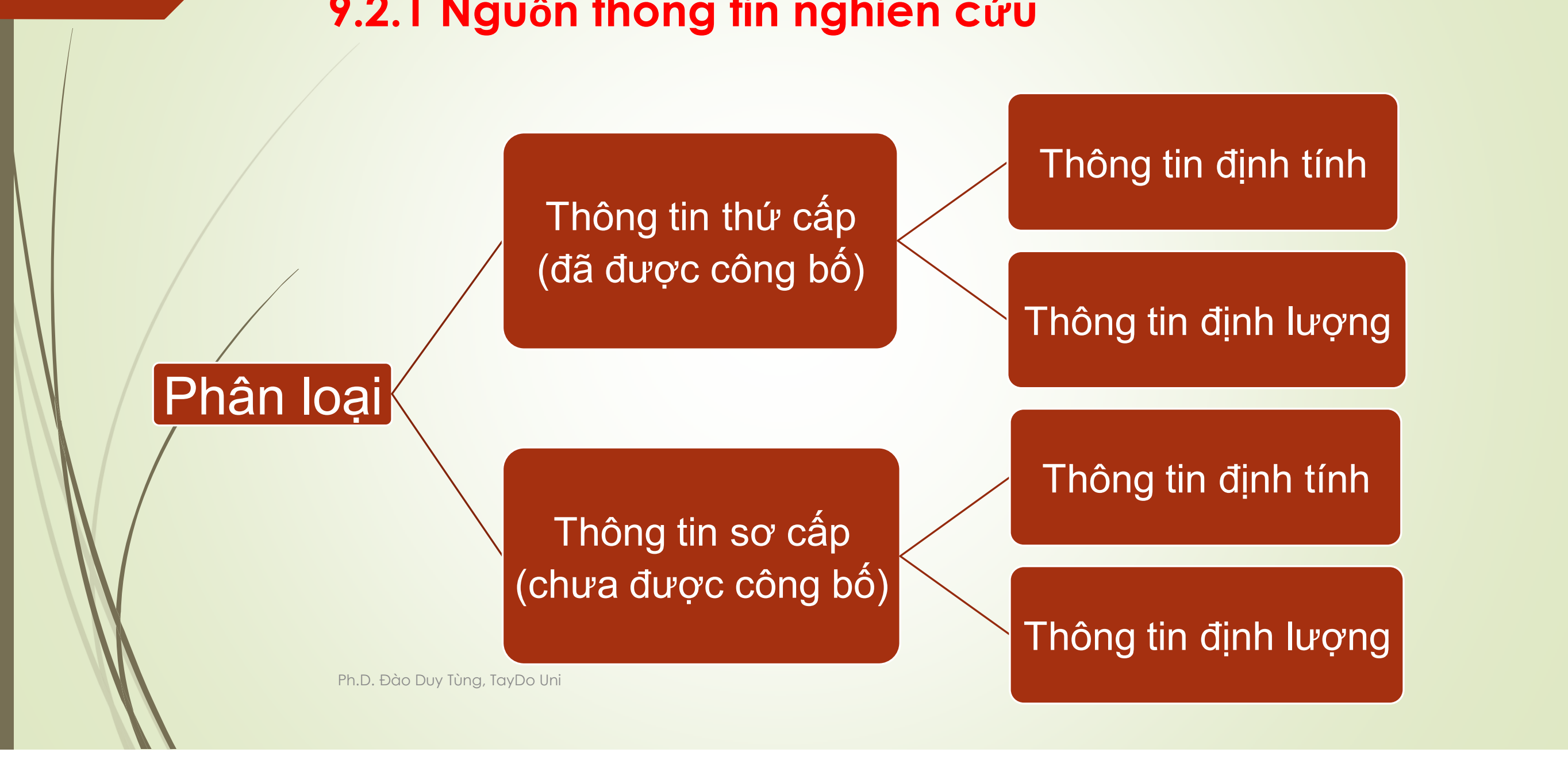




\subsection{Phân loại dữ liệu và các phương pháp thu thập dữ liệu \\ 9.2.1 Phân loại thông tin nghiên cứu}

\section{A. Dữ liệu thứ cấp (secondary data)}

* Dữ liệu thứ cấp là dữ liệu do người khác thu thập, sử dụng cho các mục đích có thể là khác với mục đích nghiên cứu của chúng ta.

* Dữ liệu thứ cấp có thể bao gồm:

- Dữ liệu chưa xử lý (dữ liệu thô)

- Dữ liệu đã xử lý

* Nguồn: Báo cáo thống kê, báo cáo nghiên cứu, bài báo, giáo trình và các tài liệu khoa học khác 


\subsection{Phân loại dữ liệu và các phương pháp thu thập dữ liệu}

17

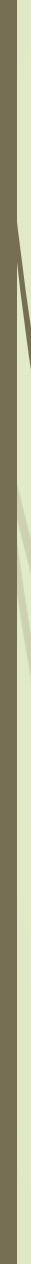

\subsubsection{Phân loại thông tin nghiên cứu}

A. Dữ liệu thứ cấp (secondary data)
Tài liệu giáo trình trong ngành, ngoài ngành

Theo chuyên ngành

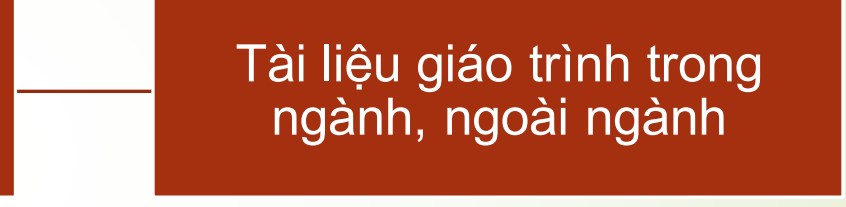

Tổng hợp báo cáo hằng tháng, bài báo khoa học, cơ sở dữ liệu, kết quả điều tra ban đầu

Thư viện, Google Scholar, báo cáo của chính phủ, Bộ, ngành, các nhà khoa học 


\section{Một số nguồn lấy dữ liệu thứ cấp đáng tin cậy}

19

Tìm kiếm tài liệu thứ cấp

Từ khoá

Tên tác giả

Tên tài liệu

Ph.D. Đào Duy Tùng, TayDo Uni

\section{Quốc tế}

- World Bank

- World Development Indicator (WDI)

- World bank Global Economic Monitor (GEM)

- IMF Data and Statistics

- Google Public Data Explorer

- United Nation Conference on Trade and Development (UNCTAD)

- ITC Trade Map

- ASEAN statistics

\section{Trong nước}

○ Tổng cục Thống kê

- Ngân hàng Nhà nước

- BộTài chính

- Bộ Lao động Thương binh và Xã hội

- Bộ Nông Nghiệp và Phát triển Nông thôn

- Bộ Công Thương

- Sở giao dịch chứng khoán

- Vietdata 


\section{Một số nguồn lấy dữ liệu thứ cấp đáng tin cậy}

\section{0}

Tìm kiếm tài liệu thứ cấp

Từ khoá

Tên tác giả

Tên tài liệu
Số liệu về tài chính, tiền tệ.

○ World Bank

- FRED

○ Tổng cục Thống kê

- Bộ Tài chính

Số liệu về tổng quan các ngành hàng và xuất nhập khẩu.

- Google Public Data Explorer

- ITC Trade Map

- UNDP

○ Bộ Công Thương

Số liệu về market và key trends trong ngành Marketing.

- Statista

- Hubspot 


\subsection{Phân loại dữ liệu và các phương pháp thu thập dữ liệu}

\section{1}

\subsubsection{Phân loại thông tin nghiên cứu}

\section{A. Dữ liệu thứ cấp (secondary data)}

Ưu điểm dữ liệu thứ cấp

$\checkmark$ Tiết kiệm thời gian, tiền bạc.

Nhược điểm dữ liệu thứ cấp

$\checkmark$ Dữ liệu thứ cấp thường đã qua xử lí nên khó đánh giá được mức độ chính xác, mức độ tin cậy của nguồn dữ liệu;

$\checkmark$ Số liệu thứ cấp này đã được thu thập cho các nghiên cứu với các mục đích khác và có thể hoàn toàn không hợp với vấn đề nghiên cứu của chúng ta;

$\checkmark$ Khó phân loại dữ liệu;

$\checkmark$ Các biến số, đơn vị đo lường có thể khác nhau.

Biện pháp khác phục

$\checkmark$ Tài liệu NC tham khảo dựa vào dữ liệu thứ cấp hay sơ cấp.

$\checkmark$ Đảm bảo tính chính xác của dữ liệu thông qua kiểm tra dữ liệu gốc 


\subsection{Phân loại dữ liệu và các phương pháp thu thập dữ liệu}

\subsubsection{Phân loại thông tin nghiên cứu}

\section{A. Dữ liệu thứ cấp (secondary data)}

\section{Trình tự thu thập dữ liệu thứ cấp:}

$\checkmark$ Xác định thông tin thứ cấp cần thu thập

$\checkmark$ Xác định nguồn, kênh thông tin thứ cấp cần lấy

$\checkmark$ Thu thập thông tin tổng quan, quá khứ

$\checkmark$ Thu thập thông tin cụ thể, cập nhật

$\checkmark$ Thu thập thông tin chuyên sâu

$\checkmark$ Tổng hợp và đánh giá 


\subsection{Phân loại dữ liệu và các phương pháp thu thập dữ liệu}

\subsubsection{Phân loại thông tin nghiên cứu}

\section{A. Dữ liệu thứ cấp (secondary data)}

Lưu ý khi thu thập dữ liệu thứ cấp:

- Sách: Thông tin tổng quan, quá khứ

- Án phẩm định kỳ (periodical article): Thông tin cụ thể, cập nhật

- Báo cáo nghiên cứu, kỷ yếu hội thảo (research report, conference proceeding book): Thu nhập thông tin chuyên sâu 


\subsection{Phân loại dữ liệu và các phương pháp thu thập dữ liệu}

\section{4}

\subsubsection{Phân loại thông tin nghiên cứu}

\section{B. Dữ liệu Sơ Cấp (primary data)}

* Dữ liệu sơ cấp là dữ liệu do chính người nghiên cứu thu thập từ các đối tượng điều tra khảo sát để phục vụ mục đích riêng của nghiên cứu.

* Số liệu/dữ liệu thô ban đầu, chưa qua tính toán, xử lý, tổng hợp, công bố.

* Nguồn: Phỏng vấn điều tra, cơ sở dữ liệu, điều tra chưa qua xử lý ... 


\subsection{Phân loại dữ liệu và các phương pháp thu thập dữ liệu}

\section{5}

\subsubsection{Phân loại thông tin nghiên cứu}

B. Dữ liệu sơ Cấp (primary data)
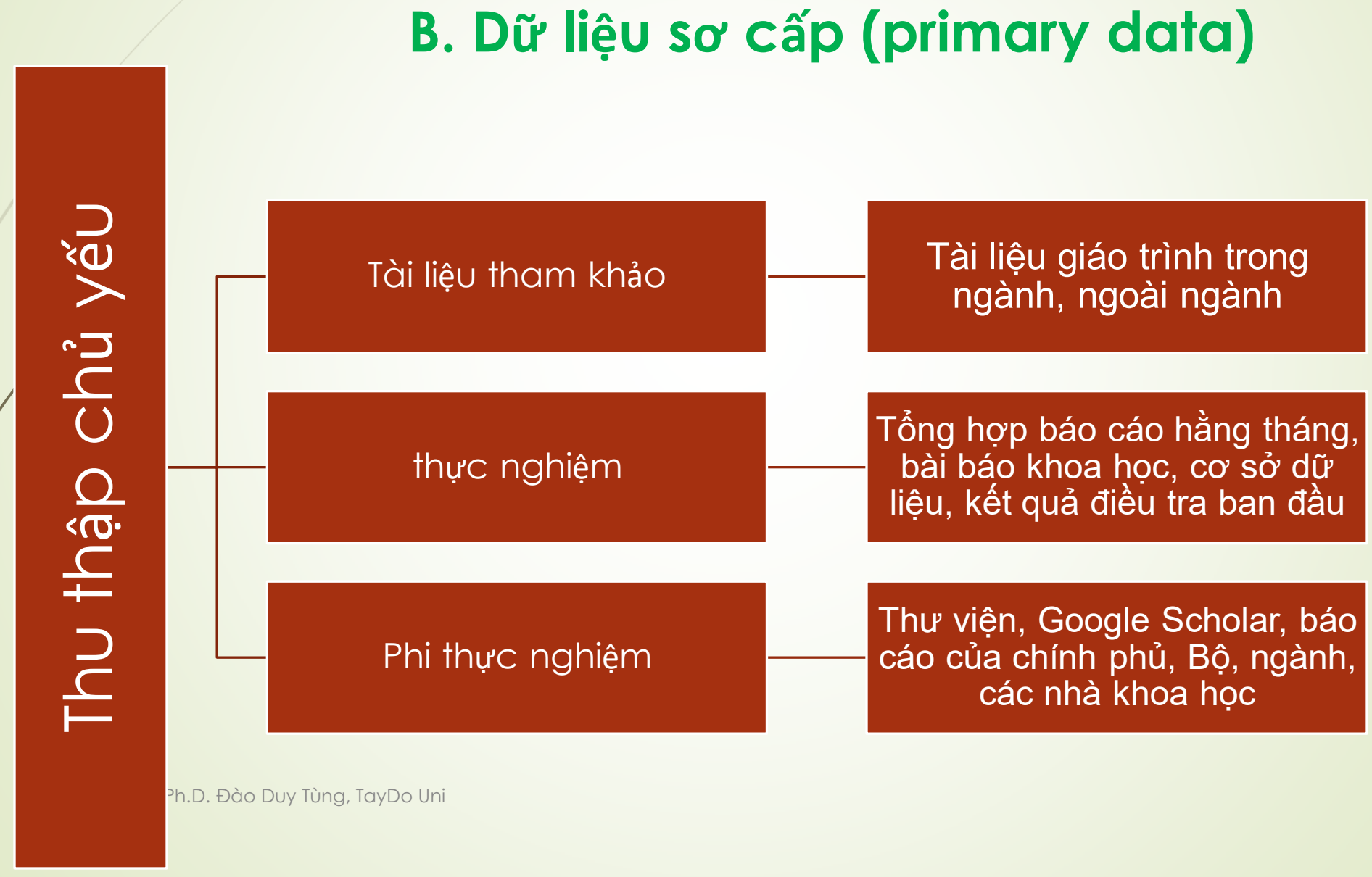


\subsection{Phân loại dữ liệu và các phương pháp thu thập dữ liệu}

9.2.1 Phân loại thông tin nghiên cứu

\section{B. Dữ liệu sơ Cấp (primary data)}

\section{Đặc điểm của dữ liệu sơ cấp}

6 Dữ liệu sơ cấp là do trực tiếp thu thập nên độ chính xác cao hơn. Tuy nhiên, dữ liệu sơ cấp phải qua quá trình nghiên cứu thực tế mới có được, vì vậy việc thu thập dữ liệu sơ cấp thường tốn nhiều thời gian và chi phí. 


\subsection{Phân loại dữ liệu và các phương pháp thu thập dữ liệu}

9.2.1 Phân loại thông tin nghiên cứu

\section{B. Dữ liệu sơ Cấp (primary data)}

Các phương pháp thu thập dữ liệu sơ cấp

$\checkmark$ Phương pháp điều tra trực tiếp

$\checkmark$ Phương pháp quan sát

$\checkmark$ Phương pháp khảo sát trực tuyến 
28

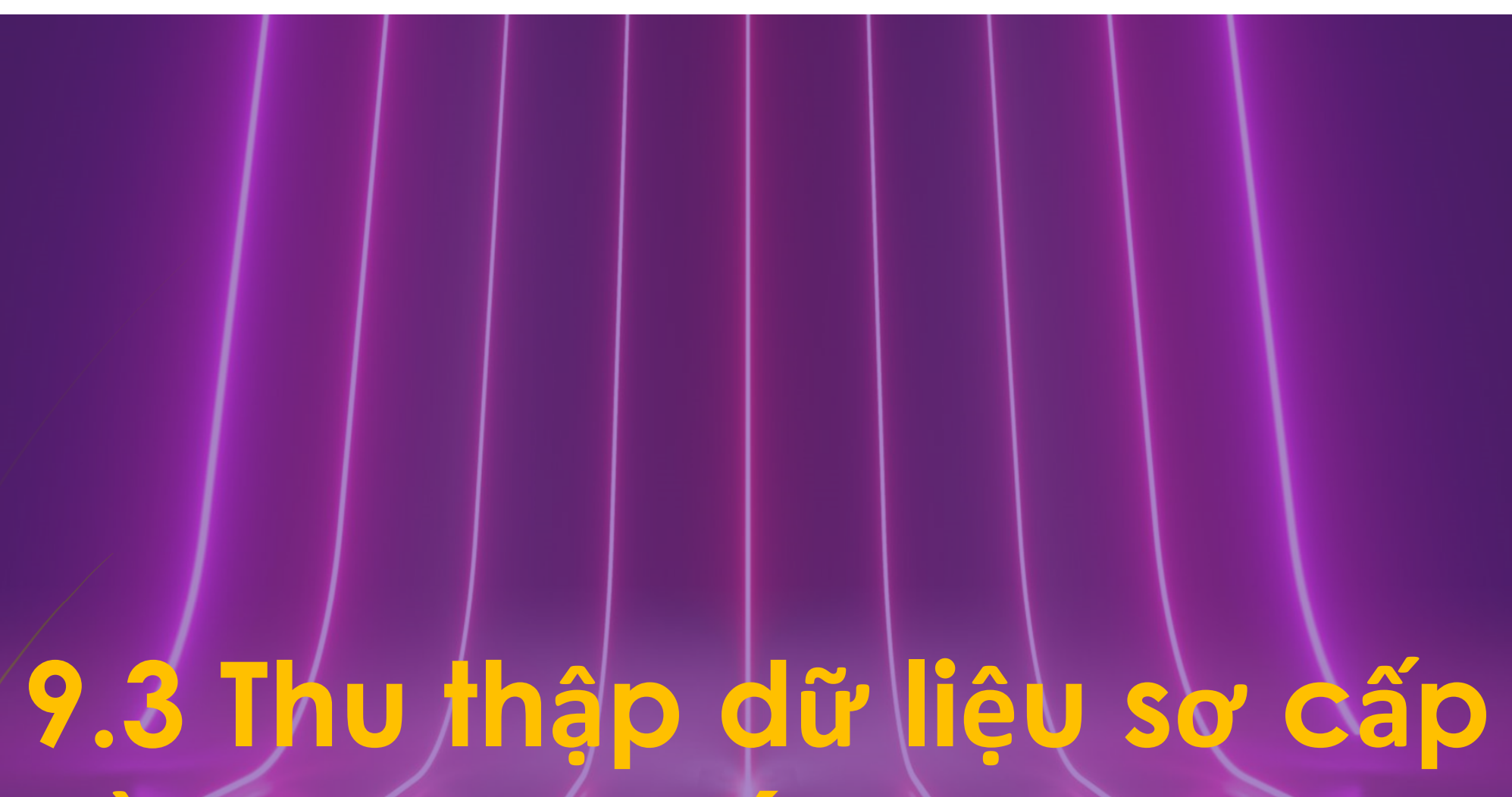
bằng quơn sát 


\subsection{Thu thập dữ liệu sơ cấp bằng quan sát}

Khám phá hành vi mua hàng vào ban đêm tại siêu thị ở Malaysia

Geiger (2007) nghiên cứu khám phá hành vi mua hàng vào ban đêm tại 1 siêu thị lớn ở Malaysia. Thiết kế nghiên cứu gồm kết hợp phương pháp thu thập dữ liệu định tính và dữ liệu định lượng. Phương pháp định tính gồm quan sát không cấu trúc và quan sát có cấu trúc. Phương pháp định lượng là phát bảng câu hỏi cho 146 người mua hàng ban đêm.
Bảng câu hỏi gồm 9 câu hỏi đóng và 1 câu hỏi mở về động cơ mua sắm, thói quen mua sắm trước và sau khi siêu thị có chế độ hoạt động 24h, nỗi lo về an toàn, vị trí của siêu thị, hành vi tham quan. 


\subsection{Thu thập dữ liệu sơ cấp bằng quan sát}

Về quan sát có cấu trúc: Người thu thập số liệu ghi nhận vào bảng biểu những dữ liệu sau về từng người trả lời: số lượng người đi theo nhóm, giới tính, món hàng mua, số tiền mua

Về quan sát không cấu trúc: Người thu thập số liệu bắt chuyện với nhân viên siêu thị, bảo vệ và quan sát người mua bước vào siêu thị. Những chú ý của người thu thập số liệu là tốc độ của khách dạo các quầy hàng, định hướng mua sắm, giao tiếp với các khách hàng khác hoặc giao tiếp với nhân viên siêu thị. Các quan sát và trò chuyện được ghi vào nhật ký hàng ngày 


\subsection{Thu thập dữ liệu sơ cấp bằng quan sát}

Việc thu thập dữ liệu diễn ra trong 1 tuần năm 2004. Khách hàng trả lời bảng câu hỏi và quan sát cấu trúc được chọn theo phương pháp chọn mẫu hệ thống như sau: cứ người thứ tư mua hàng trong khoảng thời gian từ $11 \mathrm{~g}$ trưa đến 12 giờ khuya và từ 6 giời sáng đến 7 giờ sáng; mỗi người mua từ 12 giờ khuya đến 6 giời sáng. Tổng cộng có 146 bảng câu hỏi hoàn chỉnh có thể sử dụng được và các bảng biểu dữ liệu quan sát.
Các ghi chú quan sát không cấu trúc được ghi trên 20 trang giấy. Bảng câu hỏi được phân tích trên phần mềm SPSS còn dữ liệu quan sát được phân nhóm theo nội dung để bổ sung cho dữ liệu phân tích bảng câu hỏi. Cả hai cách thu thập dữ liệu đưa ra một bức tranh khám phá về khách hàng mua sắm $24 \mathrm{~g}$. 


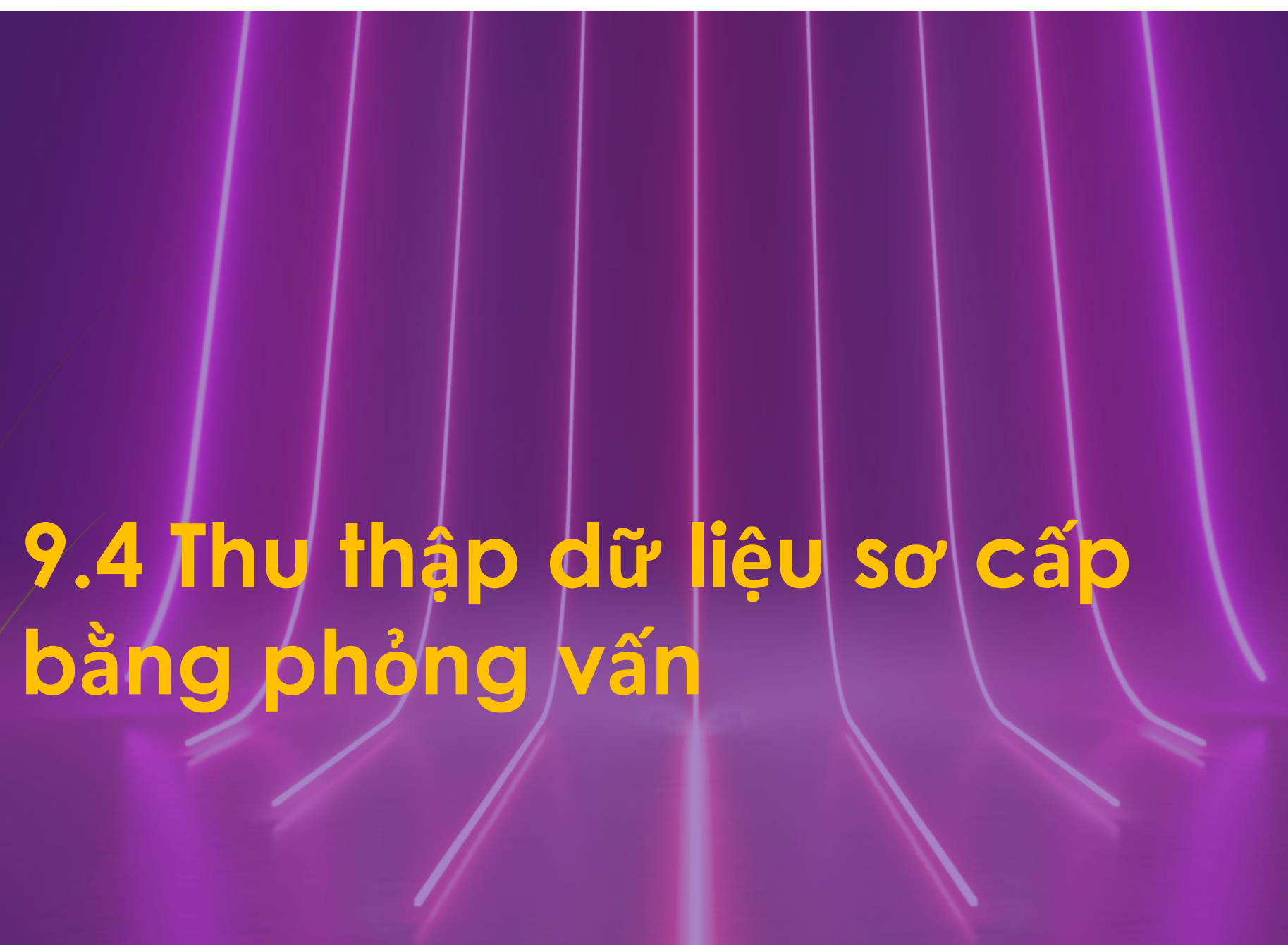




\subsection{Thu thập dữ liệu sơ cấp bằng phỏng vấn}

\subsubsection{Phỏng vấn}

\section{Phỏng vấn là:}

* Gặp gỡ, trao đổi, nói chuyện giữa 2 hay nhiều người mà có mục đích định trước.

* "Quan sát" trực tiếp (mặt đối mặt, hỏi - trả lời; thường dung câu hỏi mở.)

Các dạng phỏng vấn:

- Phỏng vấn cấu trúc

○ Có trình tự nội dung phỏng vấn

○ Câu hỏi được chuẩn bị sã̃n

- Phỏng vấn không cấu trúc

○ Linh hoạt trình tự nội dung phỏng vấn

○ Câu hỏi phỏng vấn được thay đổi theo bối cảnh thực hiện

- Phỏng vấn bán cấu trúc

○ Kết hợp linh hoạt giữa PV cấu trúc và không cấu trúc 


\subsection{Thu thập dữ liệu sơ cấp bằng phỏng vấn}

\subsubsection{Phỏng vấn}

\section{Lợi ích:}

○ Nhiều thông tin

- Khẳng định được người tham gia hiểu câu hỏi

- Giảm thiểu bỏ sót thông tin

o Có thể phân biệt rõ các câu trả lời không rõ ràng

○ Có thể phát hiện nguyên nhân sâu sa hay sự thật Hạn chế:

○ Tốn kém

○ Khó tập hợp hết người tham gia/một số có thể từ chối

- Hỏi/trả lời có thể bị chệch hoặc theo ý chủ quan

- Dư liệu nhạy cảm khó thu thập

- Nhiều khi người được phỏng vấn trả lời không theo ý mình, khó kiểm soát Ph.D. Đào Duy Tùng, TayDo Uni 


\subsection{Thu thập dữ liệu sơ cấp bằng phỏng vấn}

\subsubsection{Phỏng vấn và loại nghiên cứu}

Trong một nghiên cứu khám phá, phỏng vấn sâu có thể rất hữu ích để khám phá điều gì đang xảy ra và để tìm những hiểu biết mới.

Phỏng vấn bán cấu trúc có thể được sử dụng để hiểu các mối quan hệ giữa các biến. 
9.4 Thu thập dữ liệu sơ Cấp bằng phỏng vấn

9.4.2 Các hình thức phỏng vấn

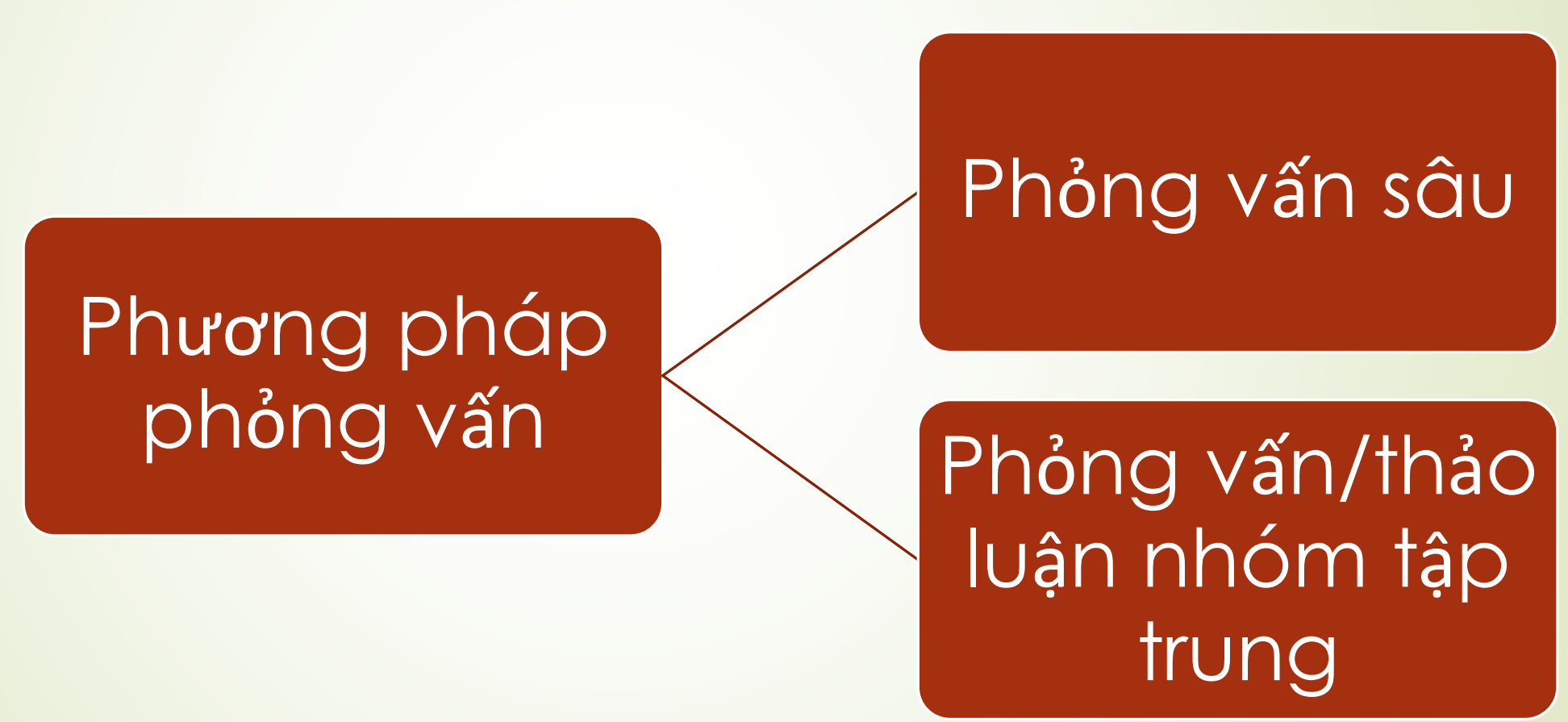




\subsection{Thu thập dữ liệu sơ Cấp bằng phỏng vấn}

\subsubsection{Các hình thức phỏng vấn}

\section{A. Phương pháp phỏng vấn sâu (in-depth interview)}

Phỏng vấn sâu là những cuộc đối thoại được lặp đi lặp lại giữa nhà nghiên cứu và người cung cấp thông tin nhằm tìm hiểu cuộc sống, kinh nghiệm và nhận thức của người cung cấp thông tin thông qua chính ngôn ngữ của người ấy.

Một số điểm quan trọng:

> Sự lặp lại của các cuộc đối thoại: Thời gian;

$>$ Cuộc đối thoại giữa nhà nghiên cứu và đối tượng: Bình đẳng;

$>$ Tìm hiểu quan điểm của đối tượng;

$>$ Tìm hiểu đối tượng trong ngôn ngữ tự nhiên của chính họ.

Những điểm hạn chế:

> Các câu trả lời không được chuẩn hóa nên khó lượng hóa;

$>$ Phỏng vấn viên có tay nghề cao và nhiều kinh nghiệm;

Ph.D. Đào Duy Viềng, Toủẩn tích tốn nhiều thời gian. 


\subsection{Thu thập dữ liệu sơ Cấp bằng phỏng vấn}

\subsubsection{Các hình thức phỏng vấn}

\section{A. Phương pháp phỏng vấn sâu (in-depth interview)}

Khi nào cần sử dụng phỏng vấn sâu?

$>$ Chủ đề nghiên cứu mới và chưa được xác định rõ;

Nghiên cứu thăm dò, khi chưa biết những khái niệm và biến số;

> Khi cần tìm hiểu sâu;

> Khi cần tìm hiểu về ý nghĩa hơn là tần số. 


\subsection{Thu thập dữ liệu sơ Cấp bằng phỏng vấn}

\subsubsection{Các hình thức phỏng vấn}

\section{A. Phương pháp phỏng vấn sâu (in-depth interview)}

Ai có thể thực hiện phỏng vấn sâu?

$>$ Người nắm rõ vấn đề nghiên cứu;

> Người được huấn luyện tốt;

> Người có kinh nghiệm trong tiếp xúc với những người thuộc các thành phần xã hội khác nhau;

$>$ Người kiên nhẫn và biết lắng nghe người khác 


\subsection{Thu thập dữ liệu sơ Cấp bằng phỏng vấn}

\subsubsection{Các hình thức phỏng vấn}

\section{A. Phương pháp phỏng vấn sâu (in-depth interview)}

Kĩ thuật phỏng vấn sâu

> Phỏng vấn không cấu trúc;

$>$ Phỏng vấn bán cấu trúc. 


\subsection{Thu thập dữ liệu sơ Cấp bằng phỏng vấn}

\subsubsection{Các hình thức phỏng vấn}

\section{A. Phương pháp phỏng vấn sâu (in-depth interview)}

Các loại câu hỏi thường sử dụng trong phỏng vấn sâu

- Câu hỏi mô tả: Yêu cầu đối tượng mô tả về sự kiện, người, địa điểm hay kinh nghiệm của họ. Được sử dụng để bắt đầu cuộc phỏng vấn làm cho đối tượng cảm thấy yên tâm vì tạo cho họ cảm giác chủ động.

- Câu hỏi đối lập: Đối tượng so sánh các sự kiện và trao đổi về ý nghĩa của các sự kiện đó.

- Câu hỏi về quan điểm/giá trị: Tìm hiểu quá trình tư duy và phân tích của đối tượng, họ nghĩ gì về những người nào đó, vấn đề, hay sự kiện nào đó. 


\subsection{Thu thập dữ liệu sơ Cấp bằng phỏng vấn}

\subsubsection{Các hình thức phỏng vấn}

\section{A. Phương pháp phỏng vấn sâu (in-depth interview) \\ Cấu trúc phỏng vấn}

\section{A. Bắt đầu cuộc phỏng vấn sâu như thế nào?}

- Giới thiệu bản thân phỏng vấn viên;

- Lời cam đoan bảo mật thông tin, địa chỉ liên hệ của người/nhóm nghiên cứu.

- Giải thích tại sao bạn lại cho rằng ý kiến/quan sát của họ về chủ đề là quan trọng. Khuyến khích họ nghĩ ra điều quan trọng.

- Yêu cầu đối tượng cho phép ghi âm cuộc phỏng vấn và ghi chép trong quá trình phỏng vấn.

- Luôn thẳng thắn và thực sự quan tâm đến những gì mà đối tượng nói với bạn.

Lưu ý: Kết thúc bảng hỏi cần có lời cám ơn. 


\subsection{Thu thập dữ liệu sơ Cấp bằng phỏng vấn}

\subsubsection{Các hình thức phỏng vấn}

\section{A. Phương pháp phỏng vấn sâu (in-depth interview) \\ Cấu trúc phỏng vấn}

\section{A. Phần giới thiệu}

- Giới thiệu bản thân phỏng vấn viên;

- Lời cam đoan bảo mật thông tin, địa chỉ liên hệ của người/nhóm nghiên cứu.

- Giải thích tại sao bạn lại cho rằng ý kiến/quan sát của họ về chủ đề là quan trọng.

- Khuyến khích họ ngắt lời bạn trong khi phỏng vấn nếu họ nghĩ ra điều gì quan trọng.

- Yêu cầu đối tượng cho phép ghi âm cuộc phỏng vấn và ghi chép trong quá trình phỏng vấn.

- Luôn thành thật và thẳng thắn và thực sự quan tâm đến những gì mà đối tượng nói với bạn.

Lưu ý: Kết thúc bảng hỏi cần có lời cám ơn. 


\subsection{Thu thập dữ liệu sơ Cấp bằng phỏng vấn}

\subsubsection{Các hình thức phỏng vấn}

\section{A. Phương pháp phỏng vấn sâu (in-depth interview) \\ Cấu trúc phỏng vấn}

\section{A. Phần giới thiệu}

- Giới thiệu bản thân phỏng vấn viên;

- Lời cam đoan bảo mật thông tin, địa chỉ liên hệ của người/nhóm nghiên cứu.

- Giải thích tại sao bạn lại cho rằng ý kiến/quan sát của họ về chủ đề là quan trọng.

- Khuyến khích họ ngắt lời bạn trong khi phỏng vấn nếu họ nghĩ ra điều gì quan trọng.

- Yêu cầu đối tượng cho phép ghi âm cuộc phỏng vấn và ghi chép trong quá trình phỏng vấn.

- Luôn thành thật và thẳng thắn và thực sự quan tâm đến những gì mà đối tượng nói với bạn.

Lưu ý: Kết thúc bảng hỏi cần có lời cám ơn. 


\subsection{Thu thập dữ liệu sơ Cấp bằng phỏng vấn}

\subsubsection{Các hình thức phỏng vấn}

\section{A. Phương pháp phỏng vấn sâu (in-depth interview)}

Các loại câu hỏi thường sử dụng trong phỏng vấn sâu

- Câu hỏi về cảm nhận: Tìm hiểu phản ứng tình cảm của đối tượng.

- Câu hỏi về kiến thức: Tìm hiểu xem đối tượng thực sự có những thông tin gì và quan điểm của họ về những điều đó.

- Câu hỏi về cảm giác: Tìm hiểu về những gì mà đối tượng nhìn thấy, nghe thấy và cảm thấy, ngửi thấy... Người được phỏng vấn mô tả về các tác động mà họ là đối tượng.

- Câuhỏivề tiểu sử: Tìm hiểu một số đặc điểm cá nhân của đối tượng. 


\subsection{Thu thập dữ liệu sơ Cấp bằng phỏng vấn}

\subsubsection{Chuẩn bị phỏng vấn}

\section{A. Phương pháp phỏng vấn sâu (in-depth interview)}

Các vấn đề liên quan

- Sự phù hợp về diện mạo của người nghiên cứu

- Phương pháp hỏi - rõ ràng và giảm sai lệch

- Sử dụng thuật ngữ chuyên biệt 


\title{
9.4 Thu thập dữ liệu sơ Cấp bằng phỏng vấn
}

\subsubsection{Chuẩn bị phỏng vấn}

\section{A. Phương pháp phỏng vấn sâu (in-depth interview)}

\author{
Các vấn đề liên quan
}

• Thể hiện kỹ năng lắng nghe và phạm vi kiểm định sự hiểu biết

- Phương pháp ghi chép dữ liệu - ghi chú và máy ghi âm

• Những khác biệt và sai lệch về văn hóa 


\subsection{Thu thập dữ liệu sơ Cấp bằng phỏng vấn}

\subsubsection{Chuẩn bị phỏng vấn}

\section{A. Phương pháp phỏng vấn sâu (in-depth interview)}

Năng lực phỏng vấn

- Mở đầu cuộc phỏng vấn

- Sử dụng ngôn ngữ thích hợp

- Cách lập câu hỏi

- Cách lắng nghe

• Kiểm định và tóm tắt những hiểu biết

- Nhận ra và cư xử với những người tham gia khó tính

- Ghi chép dữ liệu 
9.4 Thu thập dữ liệu sơ Cấp bằng phỏng vấn

50

9.4.3 Chuẩn bị phỏng vấn

A. Phương pháp phỏng vấn sâu (in-depth interview)

Thiết lập câu hỏi

Các câu hỏi mở

Các câu hỏi đóng

Các câu hỏi cụ thể và câu hỏi đóng 


\subsection{Thu thập dữ liệu sơ Cấp bằng phỏng vấn}

\subsubsection{Chuẩn bị phỏng vấn}

\section{A. Phương pháp phỏng vấn sâu (in-depth interview)}

\section{Lợi thế của việc ghi âm cuộc phỏng vấn}

- Cho phép người phỏng vấn tập trung vào việc hỏi và lắng nghe

- Cho phép việc ghi lại chính xác những câu hỏi đã nêu trong cuộc phỏng vấn, để sử dụng cho những cuộc phỏng vấn sau này khi thích hợp

- Có thể nghe lại cuộc phỏng vấn

- Có thể ghi chép chính xác và không sai lệch

- Cho phép sử dụng những lời trích dẫn trực tiếp

- Tài liệu thường xuyên dùng dài cho những tình huống khác 


\subsection{Thu thập dữ liệu sơ Cấp bằng phỏng vấn}

\subsubsection{Chuẩn bị phỏng vấn}

\section{A. Phương pháp phỏng vấn sâu (in-depth interview)}

Bất lợi của việc ghi âm cuộc phỏng vấn

- Có thể tác động bất lợi đến mối quan hệ giữa người phỏng vấn và người được phỏng vấn (khả năng 'tập trung' vào thiết bị ghi âm)

- Có thể ngăn cản một số câu trả lời của người được phỏng vấn và giảm độ tin cậy

• Khả năng gặp vấn đề về kỹ thuật

- Thời gian cần đề sao chép lại băng ghi âm 


\subsection{Thu thập dữ liệu sơ Cấp bằng phỏng vấn}

\subsubsection{Chuẩn bị phỏng vấn}

\section{B. Phương pháp thảo luận nhóm tập trung (focus group discussion)}

* Hình thức chia sẻ, trao đổi, tranh luận giữa các đối tượng nghiên cứu với nhau dưới sự hướng dẫn của người nghiên cứu (người điều khiển thảo luận) về một chủ đề phục vụ đề tài nghiên cứu.

* Trong thảo luân, người điều khiển phải dẫn dắt, gợi ý, thúc đẩy, kích thích để có được thông tin tốt từ các thành viên tham gia thảo luận.

* Nhóm thảo luận: 6 -10 người, có tính đồng nhất và đặc thù phù hợp với chủ đề thảo luận. 


\subsection{Thu thập dữ liệu sơ cấp bằng phỏng vấn}

\subsubsection{Hạn chế và cách khắc phục}

\section{B. Phương pháp thảo luận nhóm tập trung (focus group discussion)}

\section{Lợi ích:}

- Nhiều ý kiến >> Làm phong phú thông tin

- Có thể phát hiện nhiều thông tin "bí mật"

Hạn chế:

- Phụ thuộc vào người điều khiển và thành viên thảo luận

○ Thông tin thiếu tính tổng quát

- Chi phí cao về thời gian và tài chính

○ Có thể gặp khó khăn trong giao tiếp

Khắc phục:

- Chọn đúng thành viên tham gia

○ Người điều khiển có kinh nghiệm

Ph.D. Đàg Dư Tậo dựng khung cảnh thảo luận

○ Ghi âm hoăc duav lai 


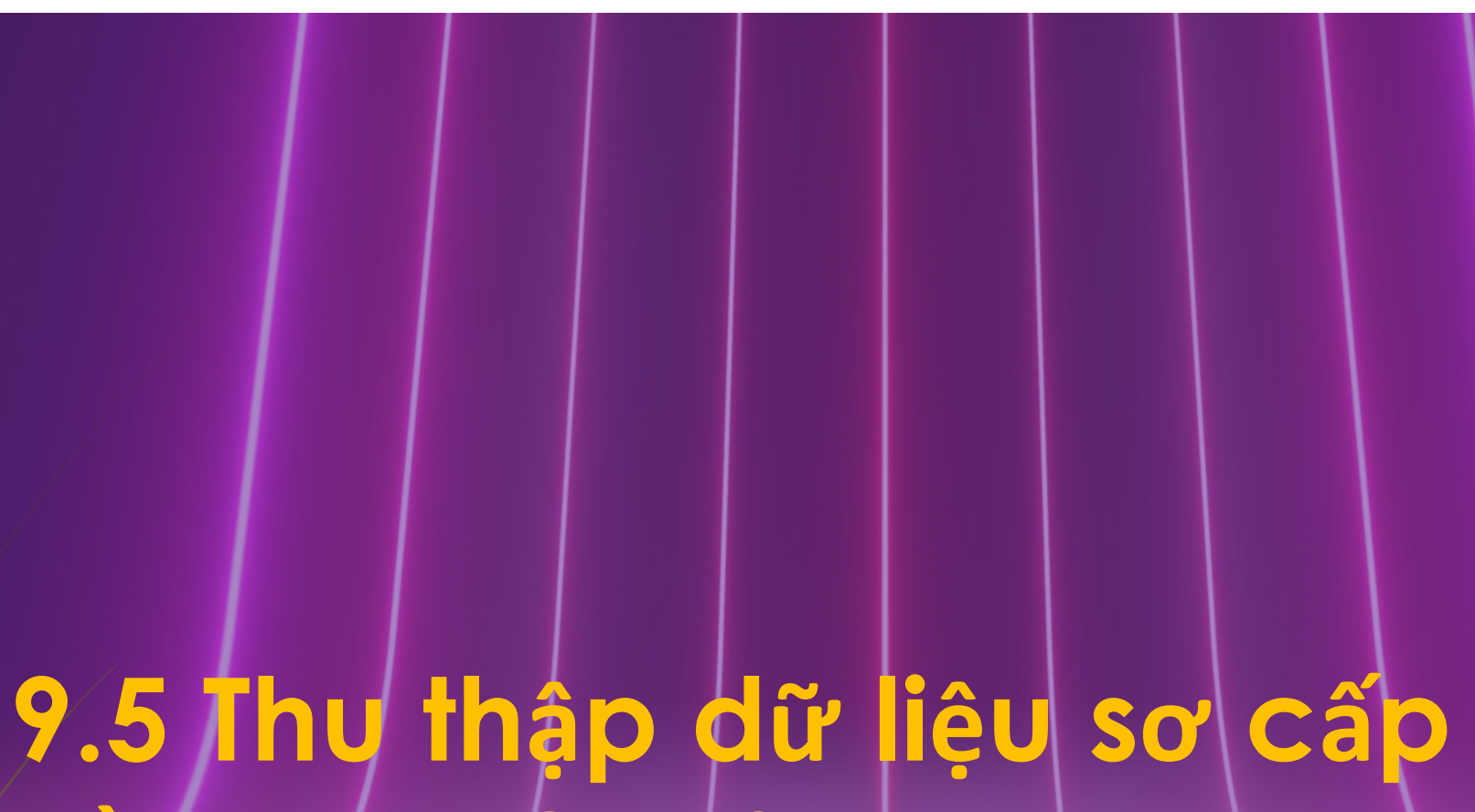
bằng phiếu đilêu tra 


\subsection{Thu thập dữ liệu sơ cấp bằng phiếu điều tra}

\subsubsection{Bảng hỏi (questionnaire, survey)}

Bảng hỏi hay còn gọi là phiếu điều tra được xem là công cụ phổ biến nhất khi thu thập các thông tin thống kê (còn gọi là dữ liệu sơ cấp).

Nó thường bao gồm một tập hợp các câu hỏi mà qua đó người được hỏi sẽ trả lời, còn nhà nghiên cứu sẽ nhận được các thông tin cần thiết. 


\subsection{Thu thập dữ liệu sơ cấp bằng phiếu điều tra}

\subsection{1 Điều tra}

* Phương pháp dùng phiếu điều tra/bảng hỏi để thu thập thông tin theo mục tiêu nghiên cứu bằng cách khảo sát một nhóm đối tượng trên một diện rộng.

* Để phát hiện các quy luật phân bố, trình độ phát triển những đặc điểm về mặt định tính và định lượng của các đối tượng cần nghiên cứu. 


\subsection{Thu thập dữ liệu sơ cấp bằng phiếu điều tra}

\subsection{1 Điều tra}

Lợi ích:

- Hiệu quả

- Giảm thời gian cho người tham gia

○ Được nhiều chủ đề Hạn chế:

o Khả năng có những câu hỏi bị chệch hoặc bị "mớm"

- Độ chính xác của số liệu phụ thuộc yêu cầu của câu hỏi

○ Tỷ lệ trả lời

Khắc phục

○ Chuẩn bị tốt bộ câu hỏi

- Điều tra thử

- Tập huấn cho điều tra viên

o Tiền trạm tốt

go. Chuẩn bịtài liệu cho điều tra 


\subsection{Thu thập dữ liệu sơ cấp bằng phiếu điều tra}

9.5.2 Phương pháp điều tra bằng phiếu điều tra là gì?

- Phương pháp điều tra bằng bảng hỏi là phương pháp phỏng vấn viết nhằm thu thập thông tin, dữ liệu sơ cấp, phục vụ cho mục đích nghiên cứu.

- Hoạt động thu thập dữ liệu được thực hiện cùng một lúc với nhiều người theo một bảng câu hỏi in sẵn, người được hỏi trả lời ý kiến của mình bằng cách đánh dấu vào các ô tương ứng theo một quy ước đã được thống nhất. 


\subsection{Thu thập dữ liệu sơ cấp bằng phiếu điều tra}

\section{Bảng hỏi}

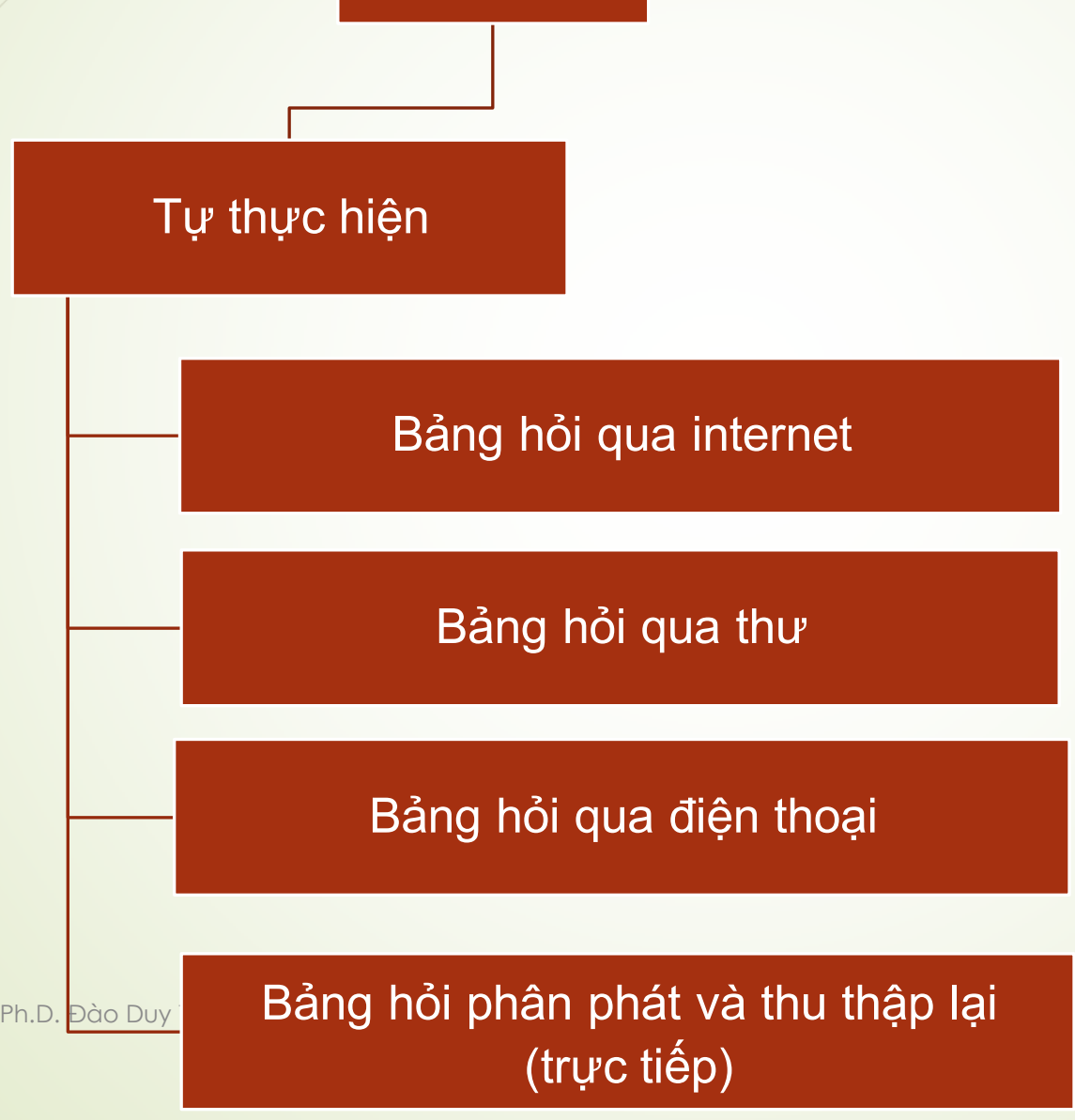




\subsection{Thu thập dữ liệu sơ cấp bằng phiếu điều tra}

\section{BẢNG HỎI TRỰC TIÉP}

THUẬN LợI

• Người phỏng vấn có thể thuyết phục đối tượng trả lời.

- Thông tin về gia cảnh có thể quan sát, không cần hỏi.

- Có thể kết hợp hỏi và dùng hình ảnh để giải thích.

- Câu hỏi dài có thể sử dụng được nhờ "nài nî" của người phỏng vấn.

- Nếu người trả lời gặp rắc rối khó hiểu, người phỏng vấn có thể giải thích cho họ.

- Chọn mẫu có thể kĩ, chính xác

\section{KHÓ KHĀN}

- Chi phí cao, hao tốn thời gian.

- Sự có mặt của người phỏng vấn, thái độ, tính khô cứng của người hỏi có thể đưa đến việc né tránh câu hỏi hay lệch lạc.

- Người trả lời biết mình có thể bị nhận diện nên ảnh hưởng đến thiện chí của họ 


\subsection{Thu thập dữ liệu sơ cấp bằng phiếu điều tra}

\section{BẢNG HỎI QUA ĐIỆN THOẠI}

\section{THUẬN LợI}

- Giảm chi phí khảo sát.

- Có thể hỏi nhiều người trong thời gian ngắn.

• Khối mẫu lớn, rải rác trên địa bàn rộng cũng có thể tiến hành nhanh.

• Tiến hành phỏng vấn từ một trung tâm nên việc chỉ đạo và huấn luyện dễ dàng hơn.

\section{KHÓ KHĀN}

- Phỏng vấn bị giới hạn trên những gì nghe được, không quan sát được gia cảnh (tình hình thực tế).

- Phải chú ý lâu trong cuộc phỏng vấn dài gặp khó khăn, khó tránh khỏi người dự vấn gác máy giữa chừng.

• Người dự vấn không nhìn thấy người phỏng vấn nên nghi ngại hoặc ác cảm.

- Chỉ có thể thực hiện được với gia đình có điện thoại, có thể trở ngại vì đường dây hỏng hay số điện thoại không đăng kí. 


\subsection{Thu thập dữ liệu sơ cấp bằng phiếu điều tra}

\section{BẢNG HỎI QUA THƯ}

\section{THUẬN Lợl}

• Người dự vấn đọc và trả lời, không bị ảnh hưởng bởi người phỏng vấn.

- Có thể trả lời khi nào thuận tiện, không bị sức ép nào.

- Có thể phỏng vấn được với địa chỉ tản mạn mà không có phương tiện truyền thông nào liên lạc được.

• Phí tổn chỉ giới hạn ở việc làm thủ tục và bưu phí

\section{KHÓ KHĀN}

• Tỉ lệ trả lời thấp và những người trả lời có thể không đại diện.

- Mất nhiều thời gian chờ đợi, có thể nhiều tuần hoặc lâu hơn.

- Không biết gì về người dự vấn và hoàn cảnh trừ khi họ viết trên bảng hỏi.

- Dự kiến phí tổn thấp có thể trở thành phí tổn cao do số thư trả lời ít.

- Người dự vấn không được khuyến khích và hướng dẫn trả lời 


\subsection{Thu thập dữ liệu sơ Cấp bằng phiếu điều tra}

9.5.3 Các bước cơ bản trong thiết kế bảng hỏi

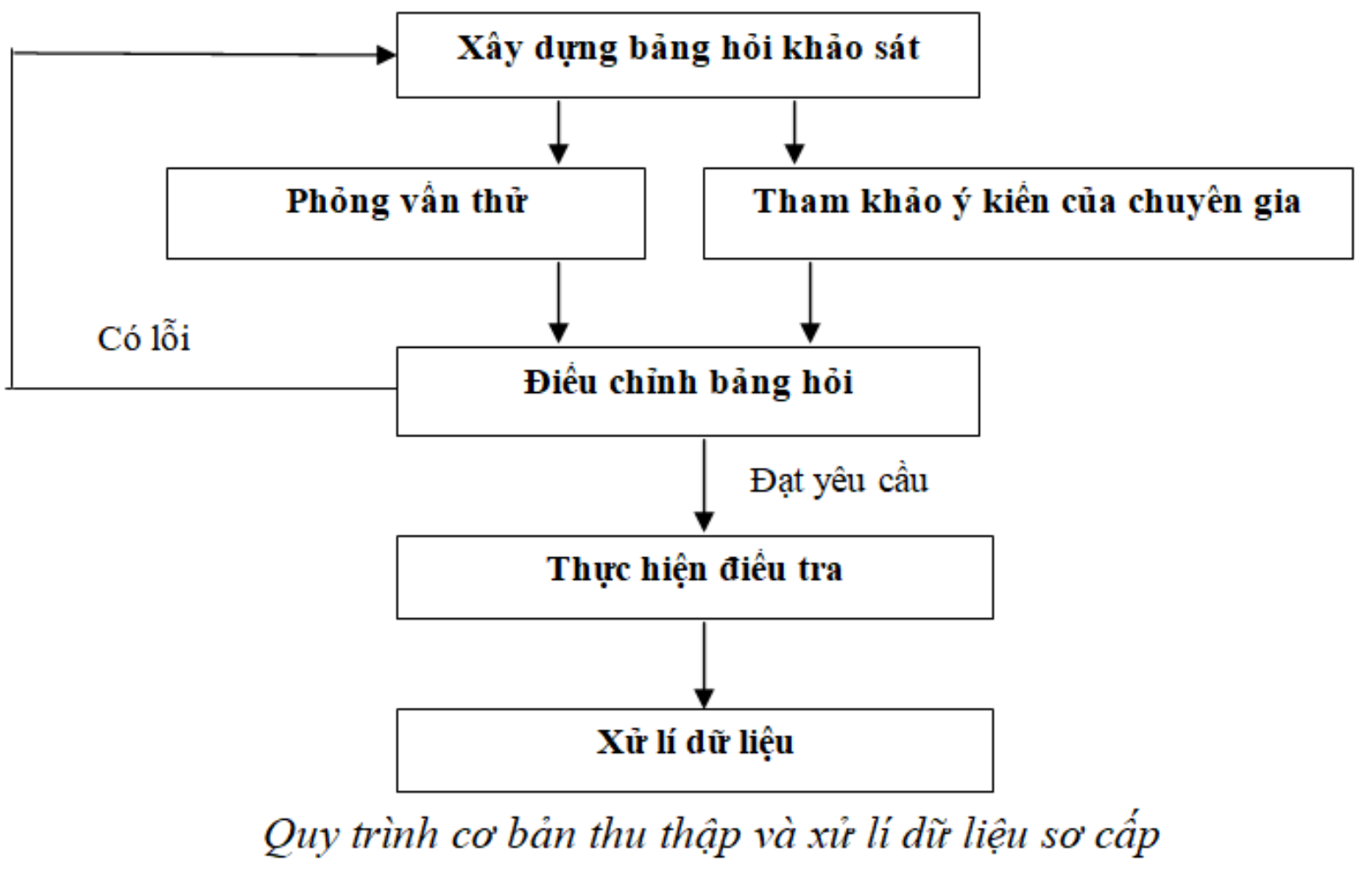

(Source: Internet) 


\subsection{Thu thập dữ liệu sơ cấp bằng phiếu điều tra \\ 9.5.4 Thiết kế bảng hỏi trong điều tra thống kê \\ Bảy bước thiết kế bảng hỏi}

\section{Bước 1: Xác định mục tiêu và câu hỏi nghiên cứu}

- Người nghiên cứu cần đảm bảo tất cả các câu hỏi được đưa ra trong bảng hỏi phù hợp với mục tiêu nghiên cứu và giúp trả lời được câu hỏi nghiên cứu đặt ra.

- Cần đảm bảo rằng tất cả các câu hỏi trong bảng hỏi sẽ giúp thu được những dữ liệu phù hợp, tránh trường hợp thiếu dữ liệu cần thiết hoặc thừa dữ liệu không cần thiết. 


\subsection{Thu thập dữ liệu sơ cấp bằng phiếu điều tra}

\subsubsection{Thiết kế bảng hỏi trong điều tra thống kê}

\section{Bảy bước thiết kế bảng hỏi}

\section{Bước 2: Xác định đối tượng khảo sát và mẫu khảo sát dụ̣ kiến}

- Mỗi một nghiên cứu sẽ hướng tới nhóm đối tượng riêng, do đó bảng hỏi được thiết kế sao cho phù hợp với mục đích và đối tượng nghiên cứu.

\section{Ví dụ:}

Đối tượng khảo sát là một nhóm người dân trong một khu vực, hay một nhóm khách hàng đang sử dụng một loại dịch vụ... Do đó, chúng ta cần xác định rõ và đúng đối tượng khảo sát, mục tiêu khảo sát để thu thập được các dữ liệu cần thiết. 


\subsection{Thu thập dữ liệu sơ cấp bằng phiếu điều tra}

\subsubsection{Thiết kế bảng hỏi trong điều tra thống kê}

\section{Bảy bước thiết kế bảng hỏi}

Bước 2: Xác định đối tượng khảo sát và mẫu khảo sát dụr kiến (tt)

- Bên cạnh đó, việc thu thập dữ liệu từ tất cả của một (hoặc các) nhóm đối tượng trong xã hội là không thể, do đó người nghiên cứu cần xác định được số lượng người trong đối tượng khảo sát (mẫu đại diện) để có được dữ liệu đại diện.

- Mẫu đại diện này cần khả thi, trong khả năng khảo sát được và là mẫu tối thiểu có giá trị thống kê, phân tích. 


\subsection{Thu thập dữ liệu sơ cấp bằng phiếu điều tra}

\subsubsection{Thiết kế bảng hỏi trong điều tra thống kê}

\section{Bảy bước thiết kế bảng hỏi}

\section{Bước 3: Xác định các cách thức thu thập dữ liệu}

Có 2 kênh chính để thu thập dữ liệu sơ cấp bằng bảng hỏi: trực tiếp và gián tiếp

- Trực tiếp: Đến gặp đối tượng khảo sát và thuyết phục họ tham gia trả lời bảng hỏi. Cách làm này mất thời gian và công sức hơn, tuy nhiên có thể thấy hiệu quả ngay tức thì với số lượng bảng hỏi được trả lời khá nhiều và nguồn dữ liệu thu được thường có độ tin cậy cao hơn.

- Gián tiếp: Gửi bảng hỏi online tới các đối tượng khảo sát qua email hoặc các diễn đàn và yêu cầu/nhờ họ trả lời. Với cách này, chúng ta sẽ không phải mất công sức đi khảo sát trực tiếp, tuy nhiên tỉ lệ trả lời thường thấp và dữ liệu thu được có thể thiếu tin cậy do các yếu tố chủ quan hoặc khách quan (người trả lời hiểu sai hoặc không hiểu câu hỏi...) 


\subsection{Thu thập dữ liệu sơ cấp bằng phiếu điều tra}

\subsubsection{Thiết kế bảng hỏi trong điều tra thống kê}

\section{Bảy bước thiết kế bảng hỏi}

\section{Bước 4: Xác định các câu hỏi trong bảng hỏi}

- Người nghiên cứu cần xác định các câu hỏi cần thiết và phù hợp trong bảng hỏi.

- Đâu là những câu hỏi cần thiết? Đó là những câu hỏi có thể thu được những dư liệu cần thiết để trả lời được các vấn đề mà nghiên cứu đặt ra và hoàn thành mục tiêu nghiên cứu. 


\subsection{Thu thập dữ liệu sơ cấp bằng phiếu điều tra}

\subsubsection{Thiết kế bảng hỏi trong điều tra thống kê}

\section{Bảy bước thiết kế bảng hỏi}

\section{Bước 5: Sắp xếp thứ tự các câu hỏi trong bảng hỏi}

- Sau khi đã xác định các câu hỏi, người nghiên cứu cần sắp xếp các câu hỏi theo thứ tự phù hợp. Việc sắp xếp thứ tự của các câu hỏi cần có sự logic để cấu trúc của bảng hỏi hợp lí, tránh gây khó khăn và phức tạp cho người khảo sát.

\section{Ví dụ:}

Những câu hỏi chung và tổng quát cần đặt trước những câu hỏi đi sâu vào chi tiết, những câu hỏi quan trọng không đặt ở cuối cùng vì khi đó, người trả lời phiếu khảo sát có thể đã quá mệt và bỏ qua hoặc không tập trung trả lời. 


\subsection{Thu thập dữ liệu sơ cấp bằng phiếu điều tra}

\subsubsection{Thiết kế bảng hỏi trong điều tra thống kê \\ Bảy bước thiết kế bảng hỏi}

\section{Bước 6: Phỏng vấn thử và tham khảo ý kiến chuyên gia}

- Một bảng hỏi được thiết kế ban đầu thường có thể gặp các lỗi như câu hỏi đa nghĩa, câu hỏi không rõ nghĩa, câu hỏi khó hiểu hoặc dễ bị hiểu sai... Do đó, ngưởi làm nghiên cứu cần khảo sát thử với một số người tham gia nằm trong nhóm đối tượng mục tiêu thông qua các cách thu thập đã xác định ở bước 3 nhằm phát hiện ra những Iỗi này. Bên cạnh đó, việc tham khảo ý kiến những chuyên gia có kinh nghiệm trong việc thiết kể bảng hỏi là điều cần thiết để có một bảng hỏi đạt yêu cầu. 


\subsection{Thu thập dữ liệu sơ cấp bằng phiếu điều tra}

\subsubsection{Thiết kế bảng hỏi trong điều tra thống kê \\ Bảy bước thiết kế bảng hỏi}

\section{Bước 7: Chỉnh sửa và hoàn thiện bảng hỏi}

Thực hiện xong bước 6 , người nghiên cứu cần những điều chỉnh cần thiết để có một bảng hỏi tốt. Sự điều chỉnh nhằm khắc phục các lỗi từ việc khảo sát thử hoặc được các chuyên gia góp ý. Một bảng hỏi tốt có thể mất nhiều lần phỏng vấn thử và điều chỉnh cho tới khi hoàn thiện. Sau khi có sự đồng thuận về bảng hỏi hoàn chỉnh, lúc này chúng ta mới bắt đầu tiến hành khảo sát thực tế. Cần lưu ý rằng kể từ lúc này, người làm nghiên cứu sẽ không chỉnh sửa bảng câu hỏi nữa để tạo sự nhất quán trong dữ liệu thu thập được (trừ trường hợp bảng hỏi mắc sai lầm mang tính trọng yếu). 
9.5 Thu thập dữ liệu sơ cấp bằng phiếu điều tra 9.5.4 Thiết kế bảng hỏi trong điều tra thống kê

Bảy bước thiết kế bảng hỏi
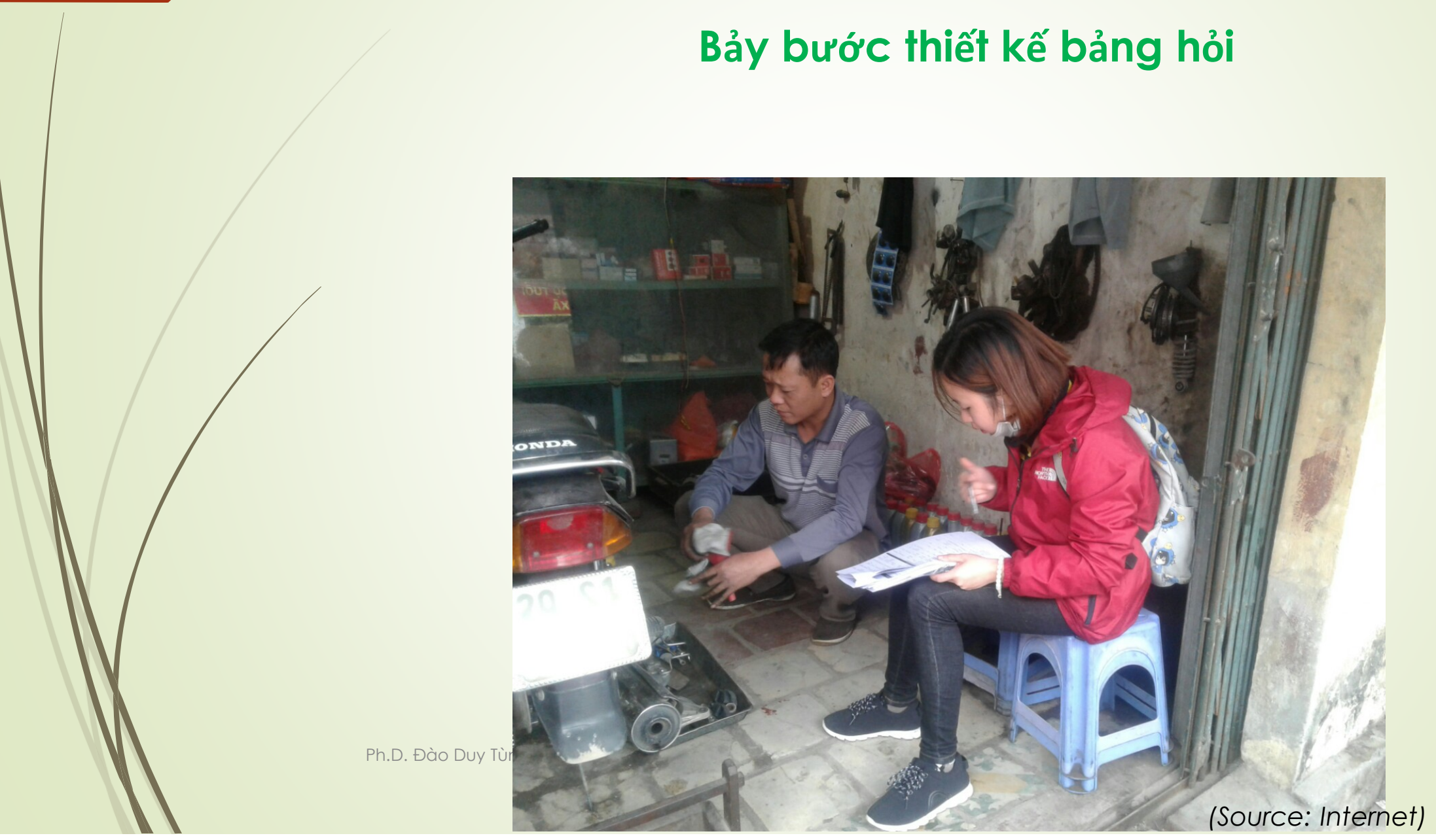


\subsection{Thu thập dữ liệu sơ cấp bằng phiếu điều tra}

\subsubsection{Thiết kế bảng hỏi trong điều tra thống kê \\ Hình thức bảng hỏi}

- Rõ ràng, trang trọng (kiểu chữ, bìa).

- Không in hai mặt.

- Không nén dòng, có đủ khoảng trống cho phần trả lời của câu hỏi mở.

- Câu hỏi phức tạp nên có phần hướng dẫn trả lời chi tiết.

- Bảng câu hỏi dài nên có trang màu phân cách từng phần.

- Cách đóng bìa thuận lợi khi lật trang. 


\subsection{Thu thập dữ liệu sơ cấp bằng phiếu điều tra}

\subsubsection{Thiết kế bảng hỏi trong điều tra thống kê}

\section{Cấu trúc bảng hỏi}

\section{A. Phần giới thiệu}

- Giới thiệu bản thân phỏng vấn viên;

- Giới thiệu lý do, mục đích nghiên cứu;

- Khoảng thời gian cần thiết để hoàn thành;

- Lời cam đoan bảo mật thông tin, địa chỉ liên hệ của người/nhóm nghiên cứu.

\section{B. Phần sàng lọc}

- Chọn đúng đối tượng để thu dữ liệu thông qua câu hỏi phân đôi.

C. Phần nội dung chính

- Đa số câu hỏi liên quan đến nội dung NC;

- Thông tin nhân khẩu học;

Phần quản lý: xác nhận, lời cam đoan.

Lưu ý: Kết thúc bảng hỏi cần có lời cám ơn. 


\subsection{Thu thập dữ liệu sơ cấp bằng phiếu điều tra}

\subsubsection{Thiết kế bảng hỏi trong điều tra thống kê}

\section{Nội dung chi tiết bảng hỏi}

\section{A. Phần giới thiệu (mẫu tiếng việt)}

Xin chào các Anh/Chị, tôi là là học viên cao học Trường . Tôi đang thực hiện luận yắn Thạc sĩ với tên đề tài là:

Tôi xin cam đoan tất cả thông tin cung cấp của Anh/Chị chỉ được sử dụng vào mục đích nghiên cứu của luận văn và được giữ bí mật tuyệt đối. Xin chân thành cảm ơn sự hợp tác của Anh/Chị.

Anh/Chị vui lòng dành chút thời gian khoảng 30 phút để giúp chúng tôi trả lời một số câu hỏi có liên quan dưới đây.

Chúng tôi rất hoan nghênh sự cộng tác và giúp đỡ của Anh/Chị. Các ý kiến trả lời sẽ được đảm bảo giữ bí mật tuyệt đối. 


\subsection{Thu thập dữ liệu sơ cấp bằng phiếu điều tra}

\subsubsection{Thiết kế bảng hỏi trong điều tra thống kê}

\section{Nội dung chi tiết bảng hỏi}

\section{A. Phần giới thiệu (mẫu tiếng anh)}

Thank you very much for your participation and support in this research. This is an ordinary academic questionnaire designed to study the "

There is no right or wrong answer. Please choose the option that is closest to the actual situation.

The questionnaire survey is conducted anonymously, and the data obtained is for scientific research purposes only.

Your personal answers will be strictly confidential.

Please feel free to answer. 


\subsection{Thu thập dữ liệu sơ cấp bằng phiếu điều tra}

\subsubsection{Thiết kế bảng hỏi trong điều tra thống kê}

\section{Nội dung chi tiết bảng hỏi}

\section{A. Phần giới thiệu (mẫu tiếng anh) (tt)}

Dear Respondent,

I am , currently doing my

The purpose of this survey is to study on the determinants of This is to investigate

Please answer all questions to the best of your knowledge. All responses collected are for academic research purpose only and will be kept strictly confidential.

Thank you for your participations for this research questionnaire. Instructions:

1) There are THREE (3) sections in this questionnaire. Please answer ALL questions in ALL sections.

2) Completion of this form will take you around 15 - 20 minutes.

3) All data collected from this survey will be kept strictly confidential.

4) This questionnaire is for from age group (i.e. 25-34 years old) 


\subsection{Thu thập dữ liệu sơ cấp bằng phiếu điều tra}

\subsubsection{Thiết kế bảng hỏi trong điều tra thống kê}

\section{Nội dung chi tiết bảng hỏi}

\section{B. Phần sàng lọc}

\section{Ví dụ 1:}

Dùng câu hỏi sàng lọc để chọn ra những phụ nữ từ 25 - 40 tuổi và có con ở độ tuổi 1 - 3 để điều tra về sữa bột "Cô gái Hà Lan"

Ta có thể dùng các câu hỏi sau:

Câu 1: Xin lỗi Chị có gia đình chưa ? (nếu có ta hỏi tiếp câu 2)

Câu 2: Vậy chị có phải là chủ hộ không ? (Nếu có ta hỏi tiếp câu 3)

Câu 3: Xin vui lòng cho biết độ tuổi của bạn theo danh sách liệt kê sau:

$$
\begin{aligned}
& \square 18 \text { - } 24 \text {--> Ngừng } \\
& \square 25-30 \\
& \square 30-40 \\
& \square>40 \text {--> Ngừng }
\end{aligned}
$$

Câu 4: Chị được mấy cháu? (chi tiết tuổi)

+ Cháu thứ $1 \ldots$ tuổi

+.Cháu thứ 2ray tuẩi

Có cháu 1 - 3 tuổi không? Nếu có ta tiếp tục, nếu không ta ngừng. 
9.5 Thu thập dữ liệu sơ cấp bằng phiếu điều tra

9.5.4 Thiết kế bảng hỏi trong điều tra thống kê

Nội dung chi tiết bảng hỏi

B. Phần sàng lọc

Ví dụ 2:

Targeted Age Group

This research is meant for participants aged 25-34 years old as of 31 December 2020 only.

Age as of 31 December 2020: *

Your answer 


\subsection{Thu thập dữ liệu sơ cấp bằng phiếu điều tra}

\subsubsection{Thiết kế bảng hỏi trong điều tra thống kê}

\section{Mã hoá bảng hỏi}

(Coding a research questionnaire)

3. Anh/Chị thuộc độ tuổi nào:

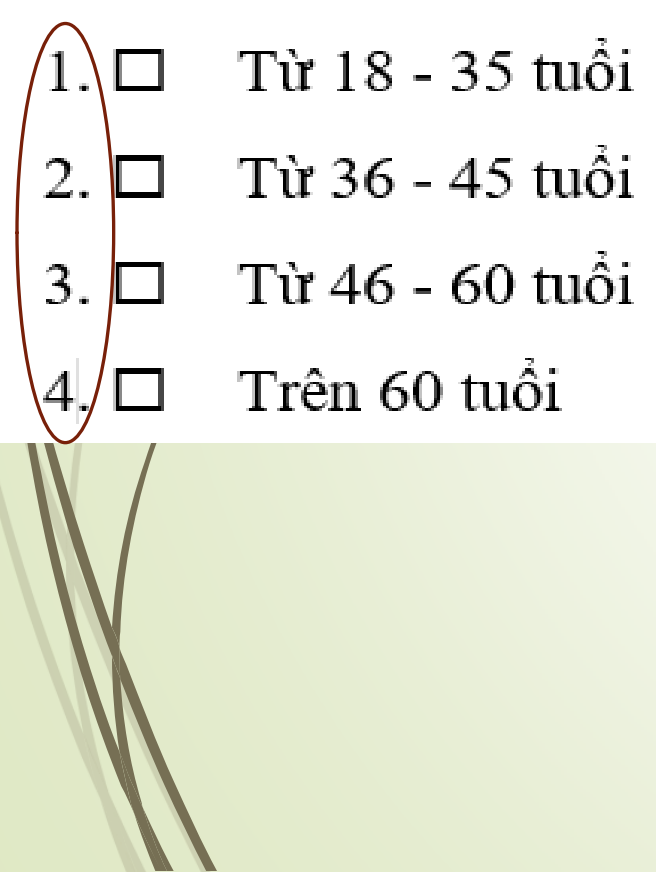

- Thiết lập cách đánh số, ký hiệu các nội dung trả lời.

- Có thể mã hóa bằng số hay bằng chữ.

- Thuận lợi cho việc xử lý, phân tích dữ liệu. 


\subsection{Thu thập dữ liệu sơ cấp bằng phiếu điều tra}

9.5.4 Thiết kế bảng hỏi trong điều tra thống kê

\section{Công cụ thu thập dữ liệu từ bảng hỏi}

Một số công cụ mà nhà nghiên cứu có thể dung để thu thập dữ liệu.

Truyền thống:

- Phát giấy

\section{Hiện đại:}

- Google Forms (Free)

- Qualtrics (Free but reports are useless);

- SurveyMonkey (Free - Paid);

- QuestionPro (Paid). 


\subsection{Thu thập dữ liệu sơ cấp bằng phiếu điều tra}

\subsubsection{Thiết kế bảng hỏi trong điều tra thống kê \\ Các dạng của câu hỏi}

\section{A. Câu hỏi mỏ̉ (Open-ended question)}

Câu hỏi mở là dạng câu có phần trả lời không định trước, đáp viên tự trả lời theo suy nghĩ của họ.

\section{Ưu điểm:}

- Khai thác ý kiến, nhận định của đáp viên;

- Tác dụng tạo quan hệ thân mật khi mở đầu;

\section{Nhược điểm:}

- Khó ghi chép, tập hợp, mã hóa, phân tích;

- Không phù hợp với dạng phỏng vấn bằng thư tín

- Khó khăn khi đáp viên trả lời dài dòng, lạc đề 


\subsection{Thu thập dữ liệu sơ cấp bằng phiếu điều tra}

\subsubsection{Thiết kế bảng hỏi trong điều tra thống kê \\ Các dạng của câu hỏi}

\section{A. Câu hỏi mỏ’ (Open-ended question)}

- Dạng câu hỏi mở tự do trả lời.

Ví dụ:

Vui lòng cho biết lý do vì sao anh/chị sử dụng cà phê hoà tan G7 ?

- Dạng câu hỏi thăm dò.

Ví dụ:

Loại cà phê hoà tan G7 có đặc tính tốt nào? Còn gì khác nữa không?

- Dạng câu hỏi dạng kỹ thuật hiện hình.

Vídu:

Loại cà phê hoà tan G7 là loại cà phê........ 


\subsection{Thu thập dữ liệu sơ cấp bằng phiếu điều tra}

\subsubsection{Thiết kế bảng hỏi trong điều tra thống kê}

\section{Các dạng của câu hỏi}

\section{B. Câu hỏi đóng (Close-ended question)}

Câu hỏi đóng là dạng câu hỏi phần để hỏi cũng như phần trả lời được cấu trúc theo dạng định trước. Phù hợp với mục tiêu của vấn đề nghiên cứu giúp cho đáp viên trả lời câu hỏi dựa theo kết cấu định sã̃n. 
9.5 Thu thập dữ liệu sơ cấp bằng phiếu điều tra 9.5.4 Thiết kế bảng hỏi trong điều tra thống kê Các dạng của câu hỏi

B. Câu hỏi đóng (Close-ended question)

- Câu hỏi phân đôi

- Câu hỏi đánh dấu tình huống theo danh sách liệt kê

- Câu hỏi xếp thứ tự

- Câu hỏi xếp hạng cho điểm

- Câu hỏi Likert/Stapel/đối nghĩa 


\subsection{Thu thập dữ liệu sơ cấp bằng phiếu điều tra}

9.5.4 Thiết kế bảng hỏi trong điều tra thống kê

\section{Các dạng của câu hỏi}

\section{B. Câu hỏi đóng (Close-ended question)}

- Câu hỏi phân đôi

Ví dụ:

Q1. Có thành viên nào trong gia đình anh (chị) hay người thân trong dòng họ hiện đang làm việc tại các công ty sản xuất kinh doanh dầu gội đầu?

1. Có -> Tạm dừng

2. Không -> Tiếp

Q2. Anh (chị) có mong muốn thay đổi việc làm hiện tại không?

1. Có

2. " Khôngng 


\subsection{Thu thập dữ liệu sơ cấp bằng phiếu điều tra}

\subsubsection{Thiết kế bảng hỏi trong điều tra thống kê}

\section{Các dạng của câu hỏi}

\section{B. Câu hỏi đóng (Close-ended question)}

- Câu hỏi đánh dấu tình huống theo danh sách liệt kê

\section{Ví dụ:}

Q1. Vui lòng cho biết các nhãn hiệu dầu gội nào khác mà anh/chị chưa từng sử dụng? Loại nào khác nữa?

Q2. Nhãn hiệu nào anh/chị đã dùng gần đây nhất?

Q3. Nhãn hiệu nào anh/chị đã dùng lần trước đó?

Q4. Nhãn hiệu nào anh/chị dùng phổ biến nhất?

\begin{tabular}{|l|c|c|c|c|}
\hline Loại nhãn hiệu & Q1 & Q2 & Q3 & Q4 \\
\hline Tigi & 1 & 1 & 1 & 1 \\
\hline Reuzel & 2 & 2 & 2 & 2 \\
\hline Billy Jealousy & 3 & 3 & 3 & 3 \\
\hline Alnnlav & 1 & 1 & 1 & 1 \\
\hline
\end{tabular}


9.5 Thu thập dữ liệu sơ cấp bằng phiếu điều tra

9.5.4 Thiết kế bảng hỏi trong điều tra thống kê

Các dạng của câu hỏi

B. Câu hỏi đóng (Close-ended question)

- Câu hỏi xếp thứ tự

Ví dụ:

Q1. Vui lòng xếp thứ tự các nhãn hiệu mà anh/chị ưa thích?

\begin{tabular}{l|l|}
\hline Loại nhãn hiệu & Q1 \\
\hline Tigi & \\
\hline Reuzel & \\
\hline Billy Jealousy \\
\hline Olaplex
\end{tabular}




\subsection{Thu thập dữ liệu sơ cấp bằng phiếu điều tra}

\subsubsection{Thiết kế bảng hỏi trong điều tra thống kê \\ Các dạng của câu hỏi}

\section{B. Câu hỏi đóng (Close-ended question)}

- Câu hỏi xếp hạng cho điểm

Ví dụ:

Q1. Dựa theo các đặc tính của dầu gội, anh/chị vui lòng so sánh để cho điểm xếp hạng chất lượng 4 loại nhãn hiệu dầu gội theo bảng sau đây [Xếp hạng theo thang điểm 5]

5: Rất tốt, 4: Tốt, 3: Trung bình, 2: Kém, 1: Rất kém

\begin{tabular}{|l|l|l|l|l|}
\hline Đặc tính của dầu gội đầu & Tigi & Reuzel & $\begin{array}{c}\text { Billy } \\
\text { Jealousy }\end{array}$ & Olaplex \\
\hline Làm sạch tóc & & & \\
\hline Làm cho tóc suông dễ chải & & & \\
\hline Giữ cho tóc không bị chẻ ngọn & & \\
\hline Giữ cho tóc không bị khô & &
\end{tabular}




\subsection{Thu thập dữ liệu sơ cấp bằng phiếu điều tra}

\subsubsection{Các loại câu hỏi thường gặp khi thiết kế bảng hỏi}

\section{Câu hỏi lọc}

- Là những câu hỏi có chức năng phân chia những người trả lời câu hỏi thành các nhóm khác nhau, để sau đó có những câu hỏi dành riêng cho từng nhóm phù hợp với nội dung cuộc nghiên cứu tránh sự dịch chuyển của các kết quả nghiên cứu.

\section{Ví dụ 1:}

Bạn hãy cho biết chỗ bạn ở hiện nay?
a. Ở nhà riêng (1)
b. Ở nhà người quen(2)
c. Ở nhà trọ (3)
d. Ở ký túc xá (4)

+ Nếu bạn ở nhà riêng xin trả lời các câu hỏi sau từ 13 -16.

+ Nếu bạn ở nhà người quen xin trả lời các câu hỏi từ 17-20.

Còn lại, bạn trả lời từ 21- 24.

\section{Ví dụ 2:}

Have you ever smoked marijuana?

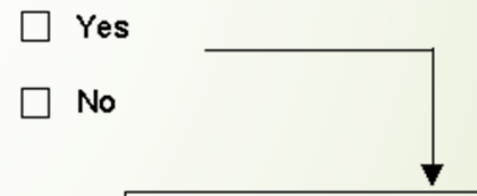

If yes, about how many times have you smoked marijuana?

$\square$ Once

$\square \quad 2$ to 5 times

$\square \quad 6$ to 10 times

$\square \quad 11$ to 20 times

$\square$ more than 20 times 


\section{Kỹ thuật đặt câu hỏi}

- Tránh sử dụng ngôn ngữ phức tạp trong giao tiếp thông thường.

- Tránh đưa ra những câu hỏi mang tính áp đặt và có ẩn ý.

- Tránh câu hỏi mơ hồ, không rõ nghĩa; phải đặt những câu hỏi cụ thể

- Tránh những câu hỏi đa nghĩa, câu hỏi gồm nhiều thành tố

- Tránh những giả thuyết trong khi nêu câu hỏi

- Tránh những câu hỏi quá thiên về việc huy động trí nhớ đề trả lời 


\section{BÀl TÂP}

"Trong gia đình ông (bà), ai là người đóng vai trò quyết định việc mua sắm các loại hàng hóa lâu bền, có giá trị cao và các hàng hóa mua thường xuyên cho tiêu dùng hàng ngày?".

$\square$ Người vợ

$\square$ Người chồng

$\square$ Cả hai cùng quyết định

là ví dụ về lỗi cần tránh nào?

(a) Tránh sử dụng ngôn ngữ phức tạp trong giao tiếp thông thường.

(b) Tránh đưa ra những câu hỏi mang tính áp đặt và có ẩn ý.

(c) Tránh câu hỏi mơ hồ, không rõ nghĩa; phải đặt những câu hỏi cụ thể

(d) Tránh những câu hỏi đa nghĩa, câu hỏi gồm nhiều thành tố

(e) Tránh những giả thuyết trong khi nêu câu hỏi

(f) Tránh những câu hỏi quá thiên về việc huy động trí nhớ đề trả lời 


\subsection{Thu thập dữ liệu sơ cấp bằng phiếu điều tra}

\subsubsection{Những nguyên tắc cần lưu ý khi thiết kế bảng hỏi}

\section{Một số nguyên tắc chung}

- Hỏi những gì bạn muốn hỏi (các câu hỏi phải đảm bảo cung cấp thông tin cần thu thập)

- Hiểu tâm lý người được phỏng vấn và hoàn cảnh phỏng vấn. Luôn coi người trả lời là một người tham gia trò chuyện một cách tình nguyện. Quan tâm đến quyền riêng tư của người trả lời.

- Đảm bảo rằng người tham gia trả lời trong các cuộc điều tra được thông tin đầy đủ những gì họ được hỏi và thông tin của họ được sử dụng như thế nào. 


\subsection{Thu thập dữ liệu sơ cấp bằng phiếu điều tra}

9.5.6 Những nguyên tắc cần lưu ý khi thiết kế bảng hỏi

\section{Một số nguyên tắc chung (tt)}

> Đảm bảo tính khuyết danh của câu trả lời. Vấn đề này được giải quyết sẽ giải quyết một loạt các vấn đề nêu trên như:

quyền cá nhân, sự đồng thuận hay sư tin tưởng của người trả lời.

> Cung cấp cho người trả lời toàn bộ các thông tin về mục đích nghiên cứu, nội dung bảng hỏi và trả lời bất kỳ câu hỏi nào về nguồn tài trợ hay việc sử dụng số liệu. Cần phải nhắc tới cả mức độ bảo mật của thông tin. 


\subsection{Thu thập dữ liệu sơ cấp bằng phiếu điều tra}

\subsubsection{Những nguyên tắc cần lưu ý khi thiết kế bảng hỏi}

\section{Từ ngữ sử dụng trong câu hỏi}

- Định nghĩa vấn đề rõ ràng bằng các từ để hỏi: Who, What, Where, When, Why, How.

- Sử dụng những từ đơn giản, thông dụng.

- Tránh sử dụng từ ngữ trừu tượng, ám chỉ thời gian không chính xác.

- Tránh câu hỏi có 2 vế song song (vừa-vừa).

- Tránh câu hỏi mang tính định kiến, gợi ý.

- Cẩn thận với các câu hỏi làm ảnh hưởng đến sĩ diện, tự ái cá nhân. 


\subsection{Thu thập dữ liệu sơ cấp bằng phiếu điều tra}

\subsubsection{Những nguyên tắc cần lưu ý khi thiết kế bảng hỏi}

\section{Từ ngữ sử dụng trong câu hỏi (tt)}

- Ý nghĩa của từ mà chúng ta định sử dụng là gì?

- Từ này có ý nghĩa nào khác nữa không?

- Nếu diễn đạt thêm ngữ cảnh có làm cho ý nghĩa được rõ ràng hơn không?

- Từ đó có nhiều hơn 1 cách diễn đạt không?

- Có bất kỳ từ nào khác có cách phát âm tương tự làm nhầm lẫn không?

- Có một hay cụm từ nào đơn giản hơn nên sử dụng thay thế không? 
9.6 Các phương pháp chọn mẫu 


\subsection{Các phương pháp chọn mẫu}

\subsubsection{Giới thiệu về các phương pháp chọn mẫu}

Khi bạn tiến hành nghiên cứu về một nhóm người, hiếm khi có thể thu thập dữ liệu từ mọi người trong nhóm đó. Thay vào đó, bạn chọn một mẫu.

\section{Chọn mẫu (sampling)}

$>$ Quá trình lựa chọn một bộ phận tương đối nhỏ từ quần thể là đại diện cho quần thể cần nghiên cứu.

> Dựa trên kết quả thu được từ mẫu, nhà nghiên cứu sẽ suy diễn rộng ra cho tổng thể 


\subsection{Các phương pháp chọn mẫu}

\section{1}

\subsubsection{Quần thể và mẫu (population và sample)}

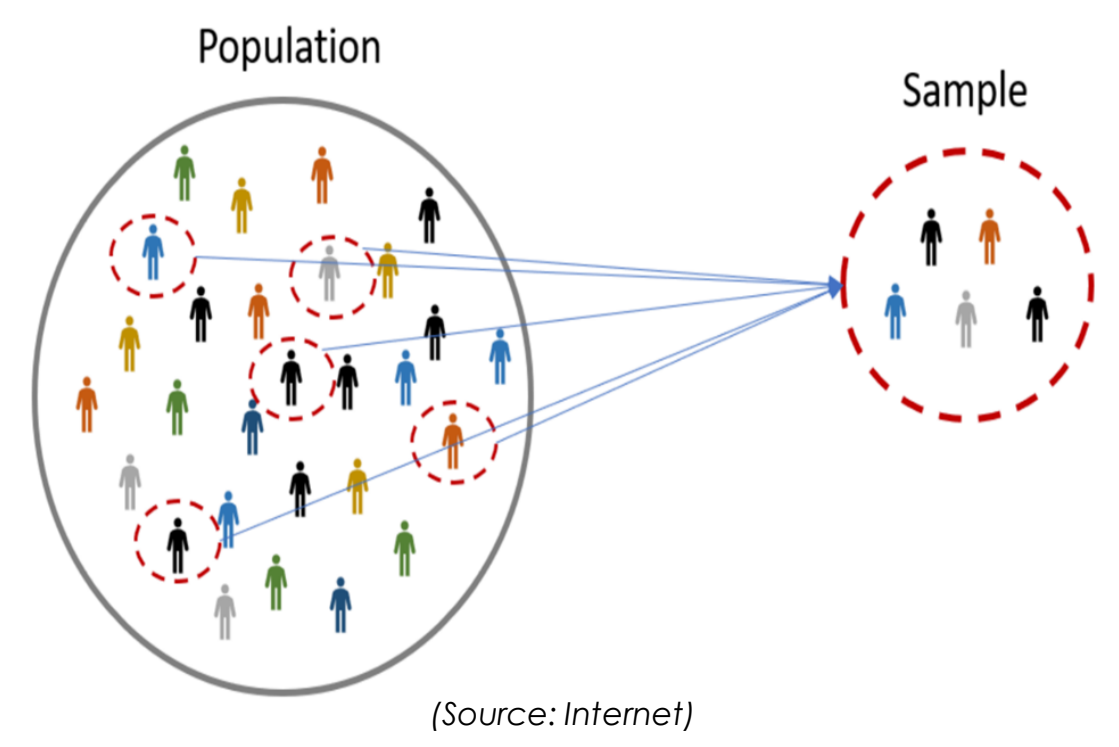

- Quần thể (population) là tập hợp tất cả các đối tượng khảo sát.

- Mẫu (sample) là là tập hợp nhỏ những cá thể lấy ra từ quần thể. Bạn sẽ thu thập những mẫu đó để tìm ra đặc trưng của mẫu. Các đặc trưng mẫu được sử dụng để suy rộng ra các đặc trưng chung của quần thể do nó làm đại diện. 


\subsection{Các phương pháp chọn mẫu}

\section{9.6.2 Quần thể và mẫu (population và sample)}

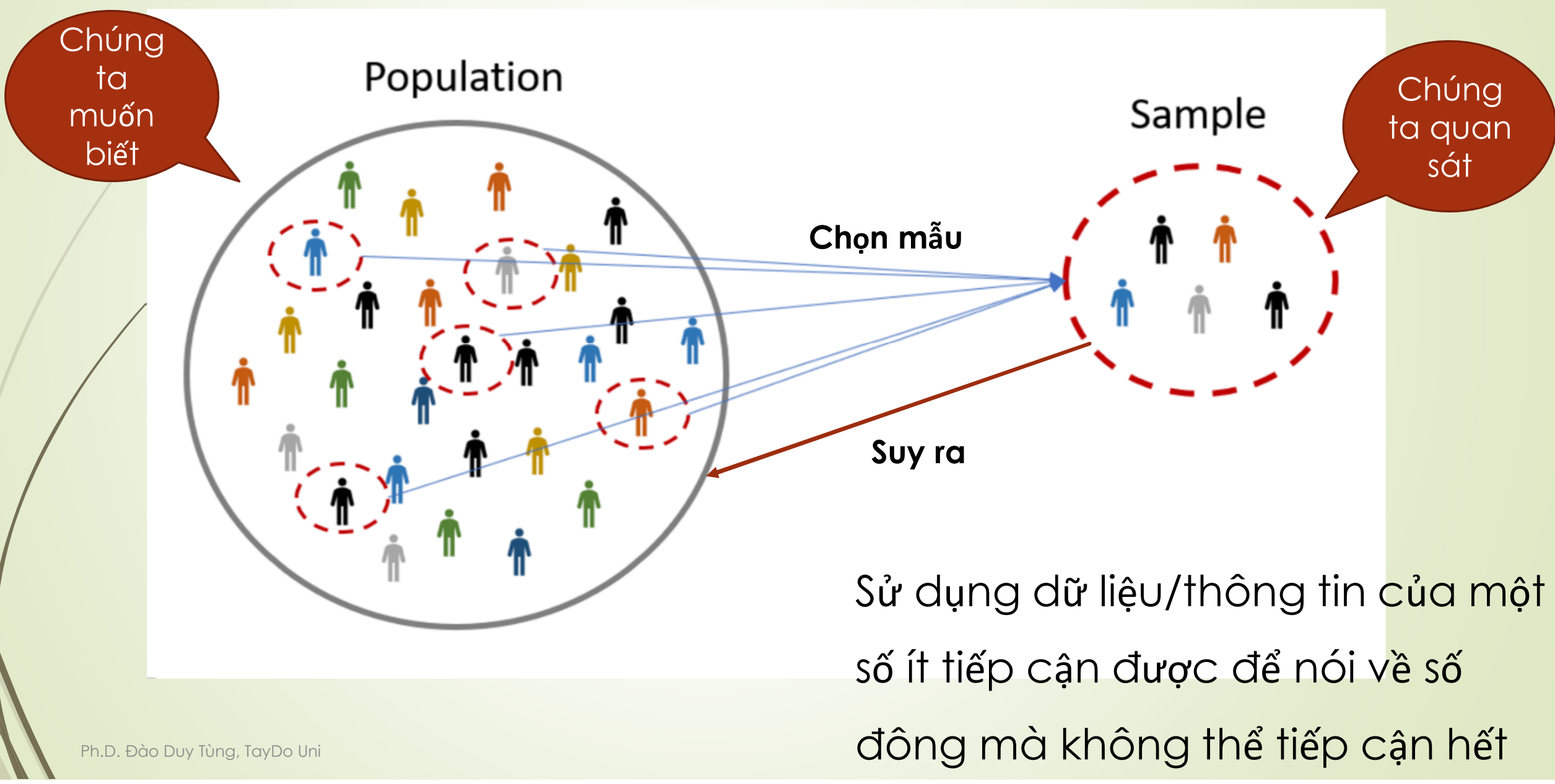




\subsection{Các phương pháp chọn mẫu}

\subsubsection{Khung mẫu (Sampling frame)}

Khung mẫu là danh sách thực tế của các cá nhân mà mẫu sẽ được lấy ra.

\section{Ví dụ}

Bạn đang nghiên cứu về điều kiện làm việc tại Công ty $X$. Quần thể của bạn là tất cả 2000 nhân viên của công ty. Khung mẫu của bạn là cơ sở dữ liệu nhân sự của công ty liệt kê tên và chi tiết liên hệ của mọi nhân viên. 


\subsection{Các phương pháp chọn mẫu}

Tại sao phải chọn mẫu?

Khi thực hiện nghiên cứu, chúng ta rất hiếm khi điều tra tổng thể, vì lý do cơ bản là hết sức tốn kém và tốn rất nhiều thời gian, công sức.

Khi điều tra chọn mẫu sẽ có nhiều lợi thế:

- Chọn mẫu cho phép tiết kiệm được thời gian và chi phí, nhân lực nếu so sánh với việc khảo sát hay điều tra toàn bộ đối tượng.

- Chọn mẫu đúng cách vẫn cho phép đạt được mức chính xác cần có của kết quả

- Chọn mẫu cho phép ta đạt tốc độ thu thập dữ liệu cao hơn, nhanh gọn và đảm bảo tính kịp thời của số liệu thống kê. 


\subsection{Các phương pháp chọn mẫu}

Tại sao phải chọn mẫu?

Khi thực hiện nghiên cứu, chúng ta rất hiếm khi điều tra tổng thể, vì lý do cơ bản là hết sức tốn kém và tốn rất nhiều thời gian, công sức.

\section{Khi điều tra chọn mẫu sẽ có nhiều lợi thế:}

- Tính sã̃n có của các phần tử tổng thể cũng là lợi thế của chọn mẫu.

- Cho phép thu thập được nhiều chỉ tiêu thống kê, đặc biệt đối với các chỉ tiêu có nội dung phức tạp, không có điều kiện điều kiện điều tra ở diện rộng.

- Việc khảo sát đôi khi làm hủy hoại hay thay đổi mẫu khảo sát, do đó không thể thử nghiệm hết toàn bộ mà chỉ thử nghiệm một số lượng mẫu nhỏ mà thôi.

- Chọn mẫu trong nghiên cứu làm giảm sai số (sai số do cân, đo, đếm, khai báo, ghi chép,...). 


\subsection{Các phương pháp chọn mẫu}

\section{Quá trình chọn mẫu}

B1: Định nghĩa quần thể và mẫu

B2: Xác định khung lấy mẫu

B3: Xác định kích thước mẫu

B4: Xác định phương pháp chọn mẫu

B5: Tiến hành lấy mẫu theo phương pháp đã chọn 


\subsection{Các phương pháp chọn mẫu}

Để đưa ra kết luận hợp lệ từ kết quả của mình, bạn phải quyết định cẩn thận cách chọn mẫu đại diện cho cả nhóm.

Có hai loại phương pháp chọn mẫu:

- Chọn mẫu phi xác suất (non-probability sampling) liên quan đến việc lựa chọn không ngẫu nhiên dựa trên sự thuận tiện hoặc các tiêu chí khác, cho phép bạn dễ dàng thu thập dữ liệu.

- Chọn mẫu xác suất (probability sampling) liên quan đến việc lựa chọn ngẫu nhiên, cho phép bạn đưa ra các suy luận thống kê mạnh mẽ về toàn bộ nhóm. 


\subsection{Các phương pháp chọn mẫu 9.6.2 Phương pháp chọn mẫu phi xác suất (Non-probability sampling)}

Trong một mẫu phi xác suất, các cá nhân được chọn dựa trên các tiêu chí không ngẫu nhiên và không phải mọi cá nhân đều có cơ hội được đưa vào. Loại mẫu này dễ dàng tiếp cận nhưng nó có nguy cơ sai lệch lấy mẫu cao hơn. Điều đó có nghĩa các kết luận bạn có thể làm về quần thể là yếu hơn so với mẫu xác suất, và kết luận của bạn có thể bị hạn chế hơn. 


\subsection{Các phương pháp chọn mẫu 9.6.2 Phương pháp chọn mẫu phi xác suất (Non-probability sampling)}

Có bốn dạng chọn mẫu phi xác suất

- Chọn mẫu thuận tiện (convenience sampling)

- Chọn mẫu theo chủ đích/phán đoán (purposes sampling/judgement sampling)

- Chọn mẫu theo định mức (quota sampling)

- Chọn mẫu quả cầu tuyết (snowball sampling) 


\subsection{Các phương pháp chọn mẫu}

111

\subsubsection{Phương pháp chọn mẫu phi xác suất}

(Non-probability sampling)

\section{Chọn mẫu thuận tiện \\ (convenience sampling)}

Convenience sample

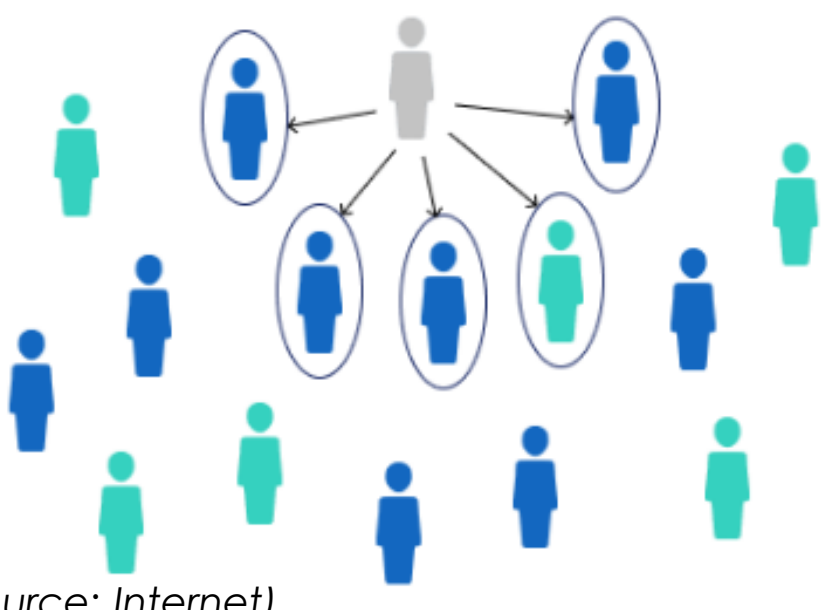

Một mẫu thuận tiện chỉ đơn giản bao gồm những cá thể mà nhà nghiên cứu dễ tiếp cận.

Đây là một cách dễ dàng và không tốn kém để thu thập dữ liệu ban đầu, nhưng không có cách nào để biết liệu mẫu có phải là đại diện cho quần thể hay không, vì vậy nó không thể tạo ra kết quả tổng quát. 


\subsection{Các phương pháp chọn mẫu}

\section{2}

\subsubsection{Phương pháp chọn mẫu phi xác suất \\ (Non-probability sampling)}

\section{Chọn mẫu thuận tiện \\ (convenience sampling)}

\section{Convenience sample}

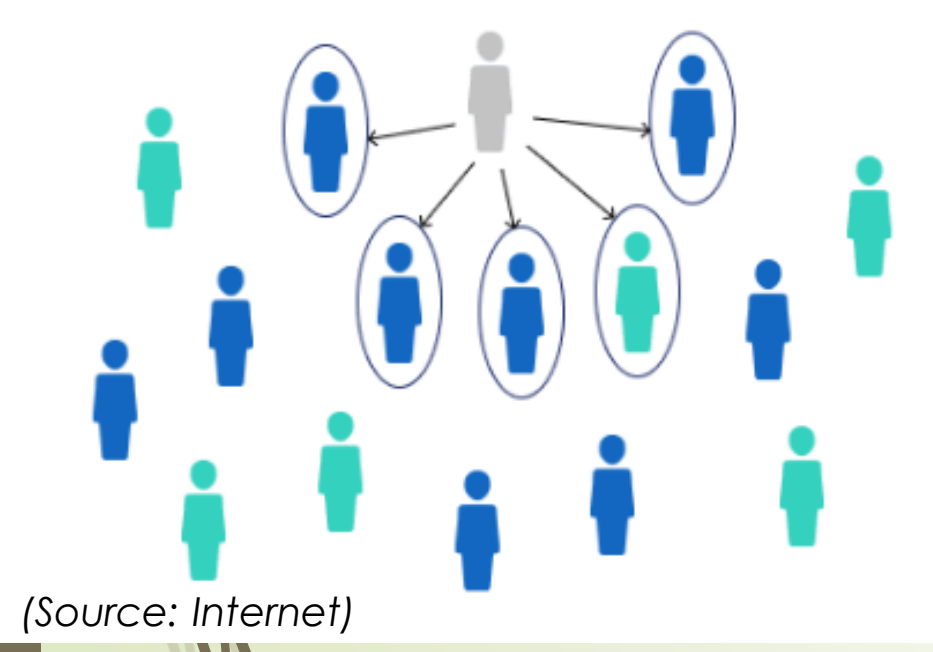

Ưu điểm:

- Chọn cá thể dựa trên sự thuận tiện, dễ tiếp cận, dễ lấy thông tin.

\section{Nhược điểm:}

- Không xác định được sai số lấy mẫu và không thể kết luận cho quần thể từ kết quả mẫu, sử dụng phổ biến khi giới hạn về thời gian và chi phí. 


\subsection{Các phương pháp chọn mẫu}

\subsubsection{Phương pháp chọn mẫu phi xác suất}

(Non-probability sampling)

\section{Chọn mẫu theo chủ đích / phán đoán \\ (purposes sampling / judgement sampling)}

Purposive sample

i

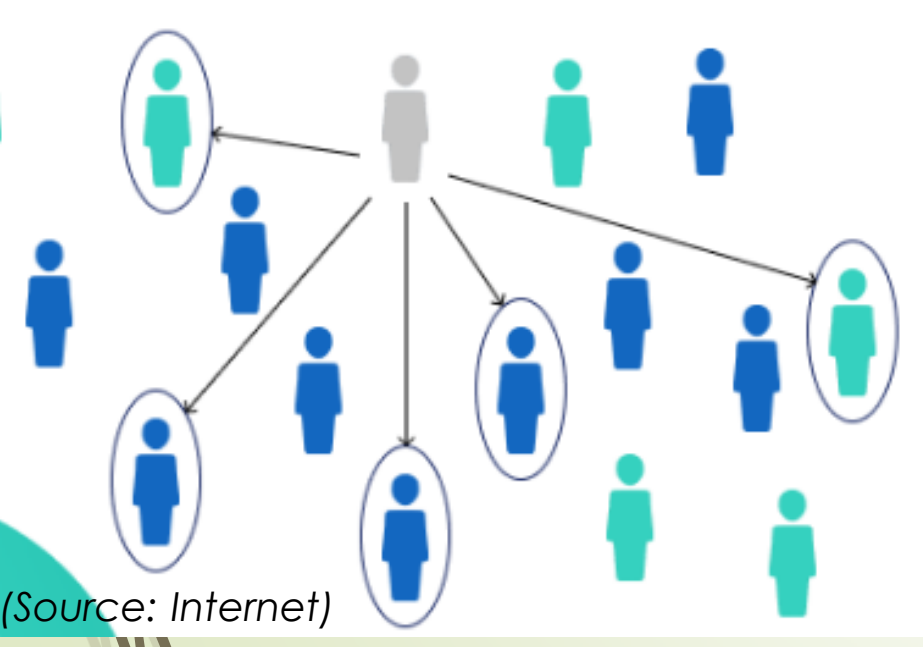

Chọn mẫu có chủ đích là cách lựa chọn dựa trên cảm quan của nhà nghiên cứu, bao gồm việc nhà nghiên cứu sử dụng kiến thức chuyên môn của họ để chọn một mẫu hữu ích nhất cho mục đích của nghiên cứu. 


\subsection{Các phương pháp chọn mẫu}

(Non-probability sampling)

\section{Chọn mẫu theo chủ đích / phán đoán \\ (purposes sampling / judgement sampling)}

\section{Purposive sample}

Loại mẫu này thường được sử dụng trong nghiên cứu định tính, nơi nhà nghiên cứu muốn có được kiến thức chi tiết về một hiện tượng cụ thể hơn là đưa ra các suy luận thống kê, hoặc khi quần thể rất nhỏ và cụ thể. Một mẫu có mục đích hiệu quả phải có tiêu chí và lý do rõ ràng để đưa vào. 


\subsection{Các phương pháp chọn mẫu}

\subsubsection{Phương pháp chọn mẫu phi xác suất \\ (Non-probability sampling)}

\section{Chọn mẫu theo chủ đích / phán đoán (purposes sampling / judgement sampling)}

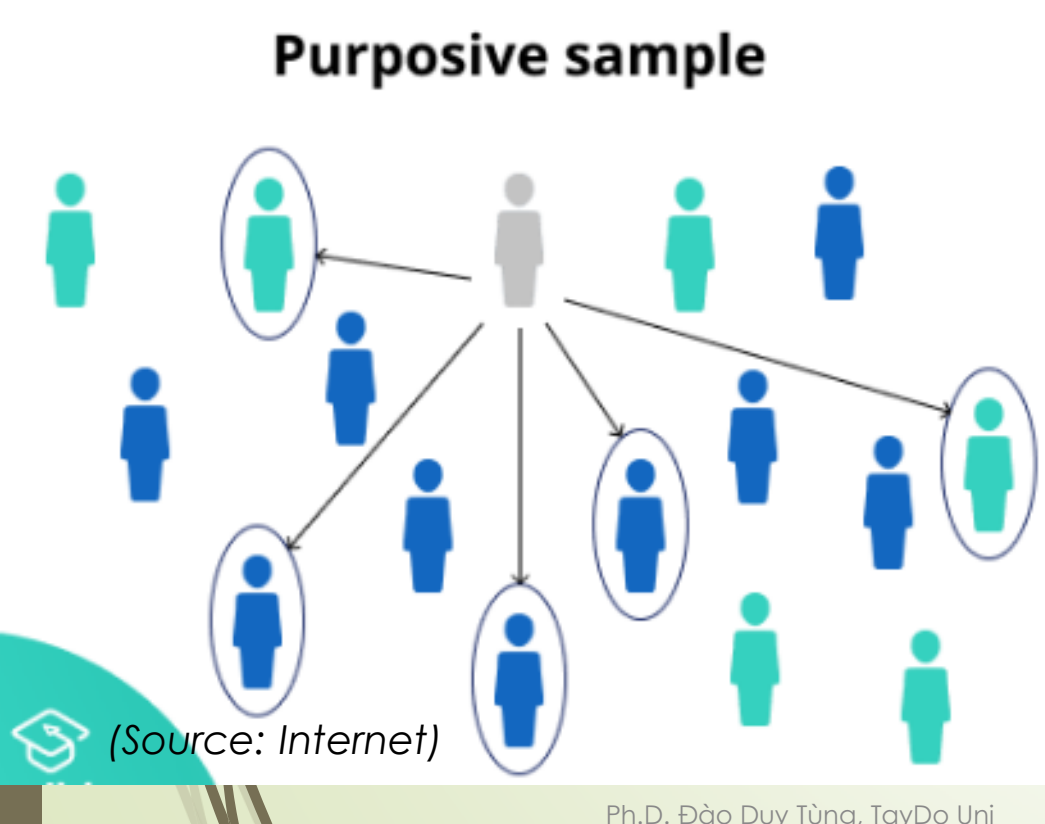

Ưu điểm:

- Giống chọn mẫu thuận tiện, nếu nhà nghiên cứu có khả năng hoặc kinh nghiệm phán đoán tốt sẽ cho mẫu tốt hơn thuận tiện.

Nhược điểm:

- Khó giải trình việc suy luận kết quả thống kê trên mẫu ra của quần thể 


\subsection{Các phương pháp chọn mẫu}

\subsubsection{Phương pháp chọn mẫu phi xác suất}

(Non-probability sampling)

\section{Chọn mẫu định mức (quota sampling)}

Đây là cách giao chỉ tiêu phải phỏng vấn/khảo sát bao nhiêu người trong thời gian qui định.

\section{Cách thực hiện:}

- Tiến hành phân tổ quần thể theo một tiêu thức nào đó mà ta đang quan tâm.

- Sau đó dùng phương pháp chọn mẫu thuận tiện hay chọn mẫu phán đoán để chọn các đơn vị trong từng tổ để tiến hành điều tra. 


\subsection{Các phương pháp chọn mẫu}

9.6.2 Phương pháp chọn mẫu phi xác suất (Non-probability sampling)

Chọn mẫu định mức (quota sampling)

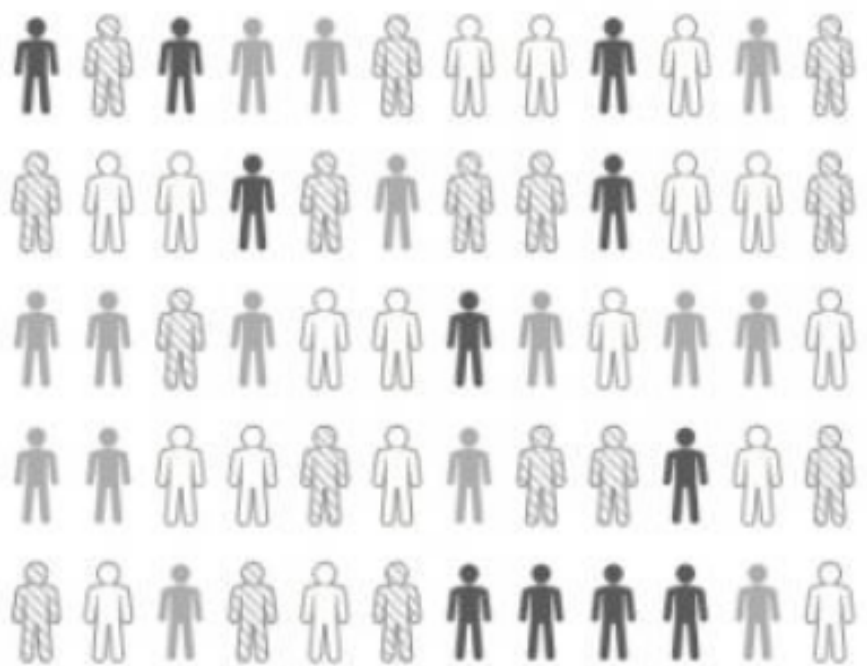

\begin{tabular}{|c|c|c|}
\hline Symbol & Age Group & No \\
\hline n̊ & 11-21 Years & 11 \\
\hline 87 & 22-31 Years & 16 \\
\hline 雨 & $32-41$ Years & 15 \\
\hline 40 & 42-51 Years & 18 \\
\hline Total & $11-51$ Years & 60 \\
\hline
\end{tabular}




\subsection{Các phương pháp chọn mẫu}

118

\subsubsection{Phương pháp chọn mẫu phi xác suất (Non-probability sampling)}

\section{Chọn mẫu quả cầu tuyết}

(snowball sampling)

\section{Snowball sample}

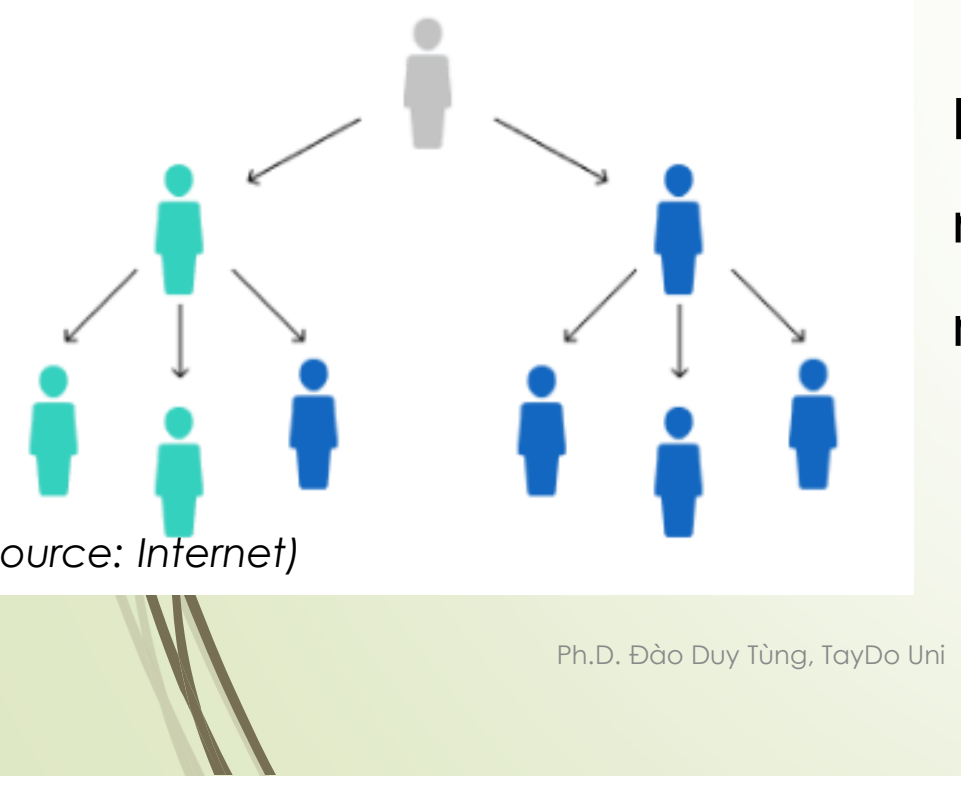

Nếu quần thể khó tiếp cận, có thể sử dụng phương pháp lấy mẫu quả cầu tuyết để tuyển người tham gia thông qua những người tham gia khác. 


\subsection{Các phương pháp chọn mẫu}

\subsubsection{Phương pháp chọn mẫu phi xác suất}

(Non-probability sampling)

\section{Chọn mẫu quả cầu tuyết} (snowball sampling)

Snowball sample

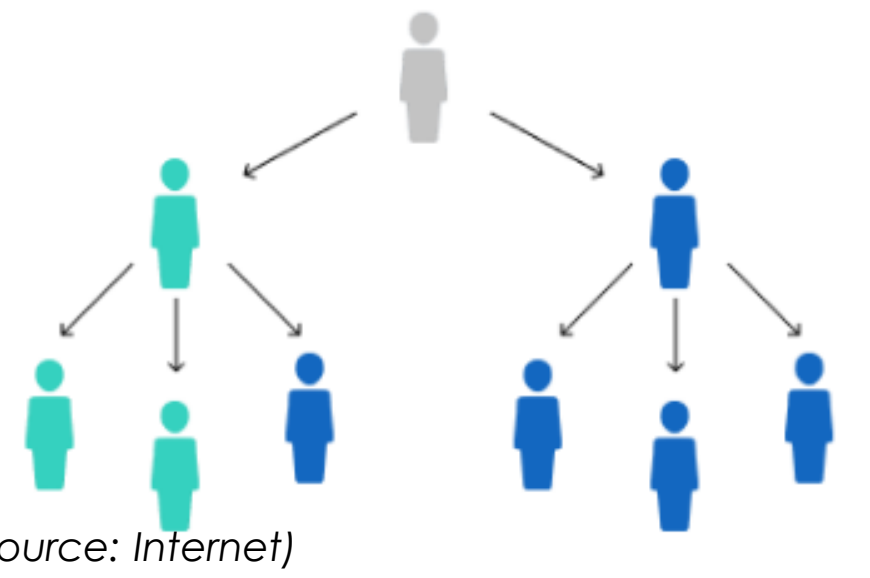

Ưu điểm:

- Chi phí thấp

- Hữu ích trong một số trường hợp

Nhược điểm:

- Khó giải trình việc suy diễn kết quả thống kê trên mẫu của quần thể. 


\subsection{Các phương pháp chọn mẫu}

9.6.3 Phương pháp chọn mẫu xác suất (Probability sampling)

Lấy mẫu theo xác suất có nghĩa là mọi thành viên của quần thể đều có cơ hội được chọn.

Loại mẫu này chủ yếu được sử dụng trong nghiên cứu định lượng. Nếu bạn muốn tạo ra kết quả đại diện cho toàn bộ tổng thể, kỹ thuật lấy mẫu xác suất là lựa chọn hợp lệ nhất. 


\subsection{Các phương pháp chọn mẫu}

\subsubsection{Phương pháp chọn mẫu xác suất \\ (Probability sampling)}

Có bốn dạng chọn mẫu xác suất

- Chọn mẫu ngẫu nhiên đơn (simple random sampling)

- Chọn mẫu hệ thống (systematic sampling)

- Chọn mẫu phân tầng (stratified sampling)

- Chọn mẫu cụm (cluster sampling) 


\subsection{Các phương pháp chọn mẫu}

125

\subsubsection{Phương pháp chọn mẫu xác suất \\ (Probability sampling)}

\section{Chọn mẫu ngẫu nhiên đơn} (simple random sampling)

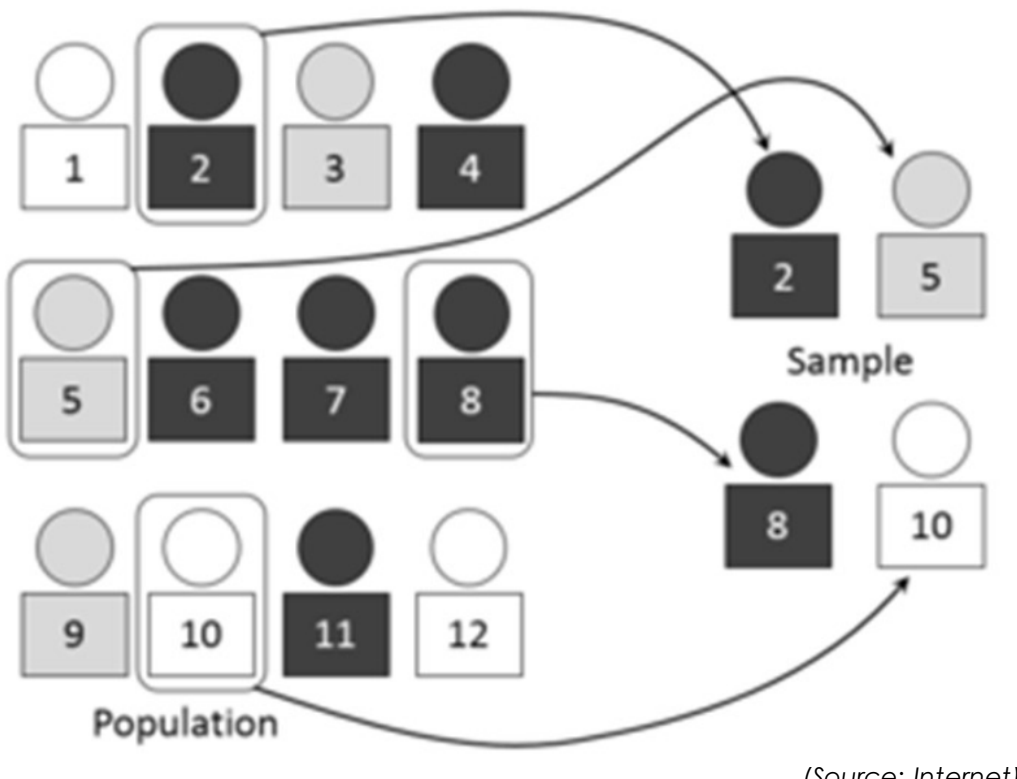

(Source: Internet)
Trong một mẫu ngẫu nhiên đơn, mỗi cá thể của quần thể được lựa chọn với xác suất như nhau vào mẫu.

\section{Cách thực hiện:}

- Lập danh sách tất cả các cỡ mẫu và đánh số thứ tự

- Chọn ngẫu nhiên các cỡ mẫu từ danh sách. Để đảm bảo tính ngẫu nhiên, có thể quay số, hoặc chọn ngẫu nhiên bằng phần mềm máy tính. 


\subsection{Các phương pháp chọn mẫu}

126

\subsubsection{Phương pháp chọn mẫu xác suất \\ (Probability sampling)}

Chọn mẫu ngẫu nhiên đơn

(simple random sampling)

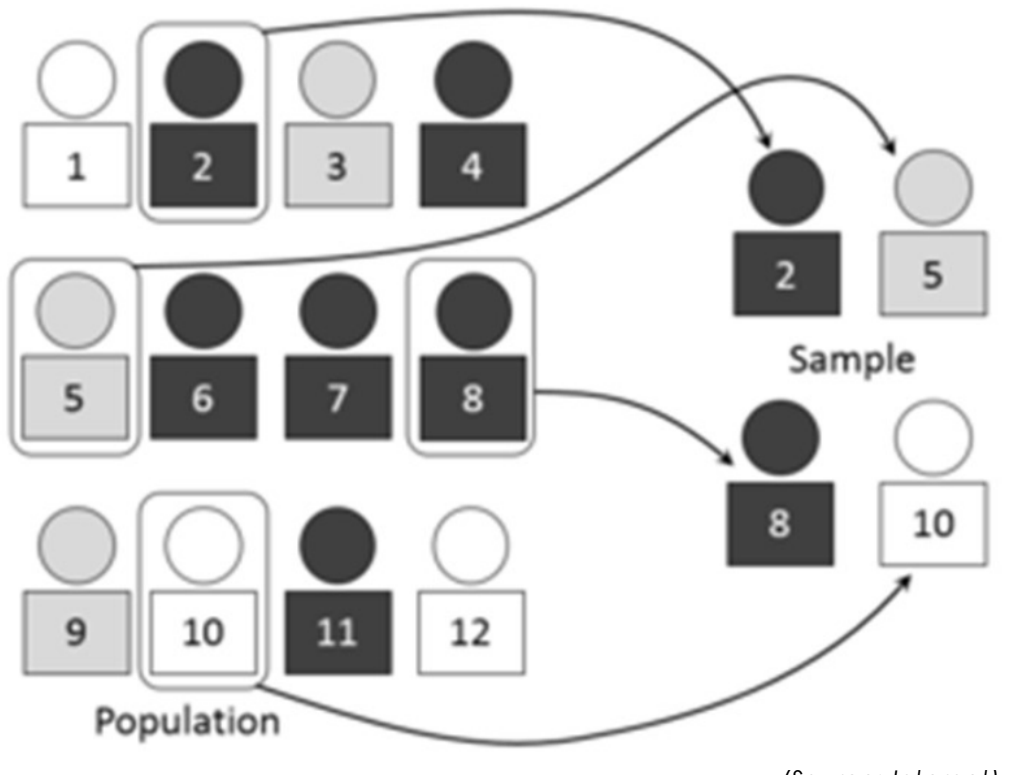

(Source: Internet)

Ưu điểm:

- Cách làm đơn giản, tính đại diện cao;

- Có thể lồng vào các kỹ thuật chọn mẫu khác.

Nhược điểm:

- Cần phải có khung mẫu;

- Các cá thể được chọn vào cỡ mẫu có thể phân bố tản mạn trong quần thể, do vậy việc thu thập số liệu tốn kém và mất thời gian. 


\subsection{Các phương pháp chọn mẫu}

(Probability sampling)

\section{Chọn mẫu hệ thống}

(systematic sampling)

Chọn ngẫu nhiên một điểm xuất phát, dựa vào bước nhảy để xác định các phần tử tiếp theo.

\section{Cách thụ̂c hiện:}

- Lập danh sách các phần tử và đánh số thứ tự;

- Chọn từ danh sách các phần tử có vị trí cách đều nhau sao cho đủ cỡ mẫu quy định. 


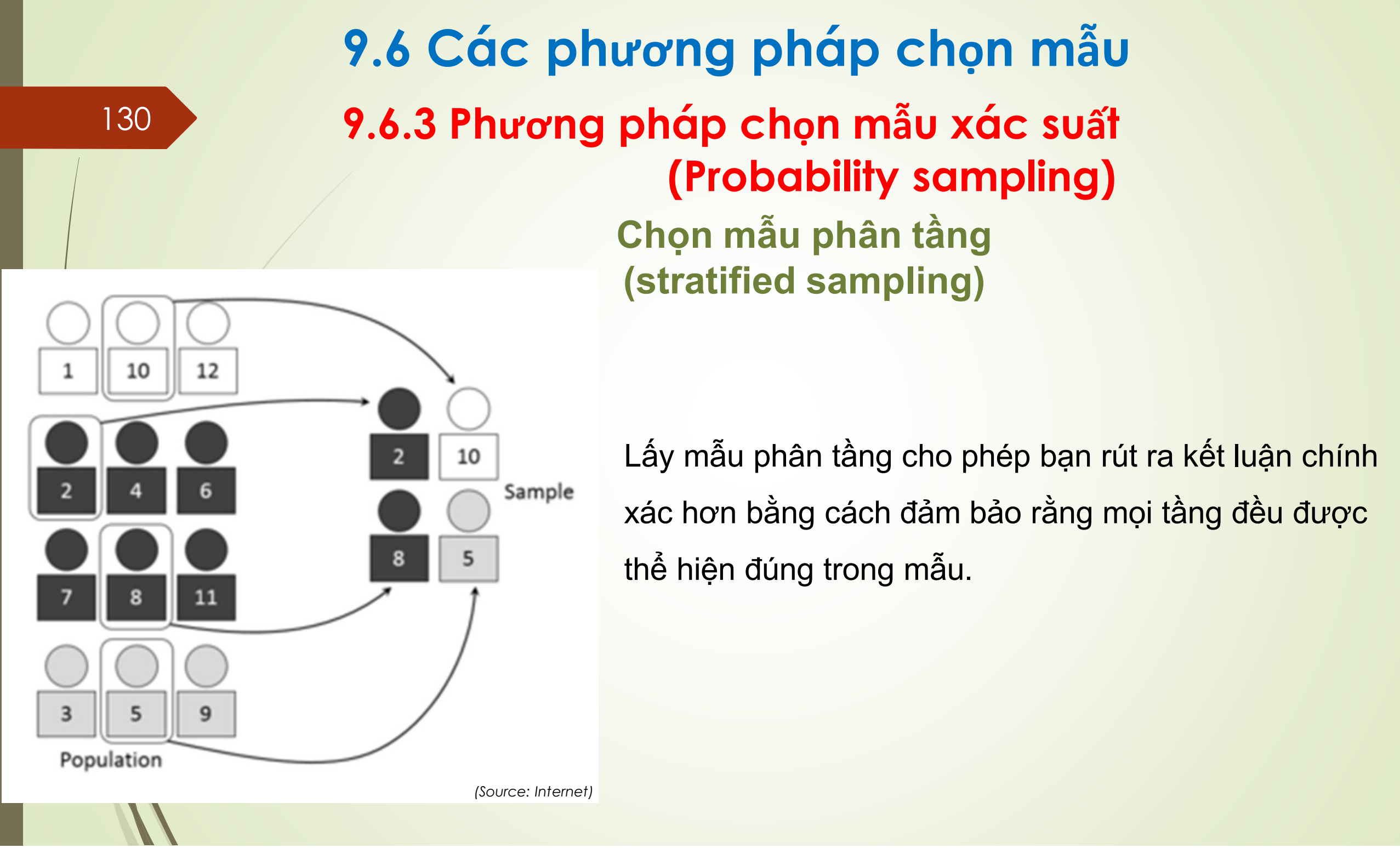




\subsection{Các phương pháp chọn mẫu}

131

\subsubsection{Phương pháp chọn mẫu xác suất \\ (Probability sampling)}

Chọn mẫu phân tầng (stratified sampling)

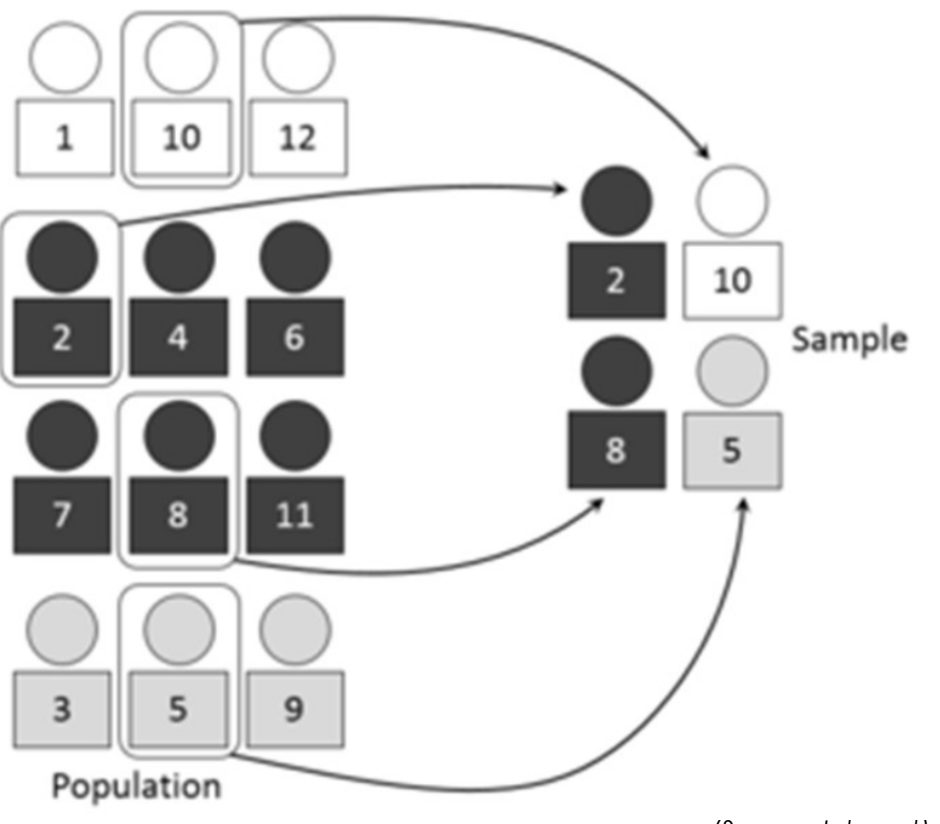

Cách thụ̂c hiện:

- Quần thể được chia ra nhiều tầng (strata) theo nguyên tắc: "cùng tầng đồng nhất, khác tầng dị biệt".

- Để chọn phần tử trong mỗi tầng: có thể dùng p.p. hệ thống.

- Số phần tử trong mỗi tầng được xác định theo tỷ lệ hoặc không theo tỷ lệ với kích thước tổng thể. 


\subsection{Các phương pháp chọn mẫu}

\subsubsection{Phương pháp chọn mẫu xác suất}

(Probability sampling)

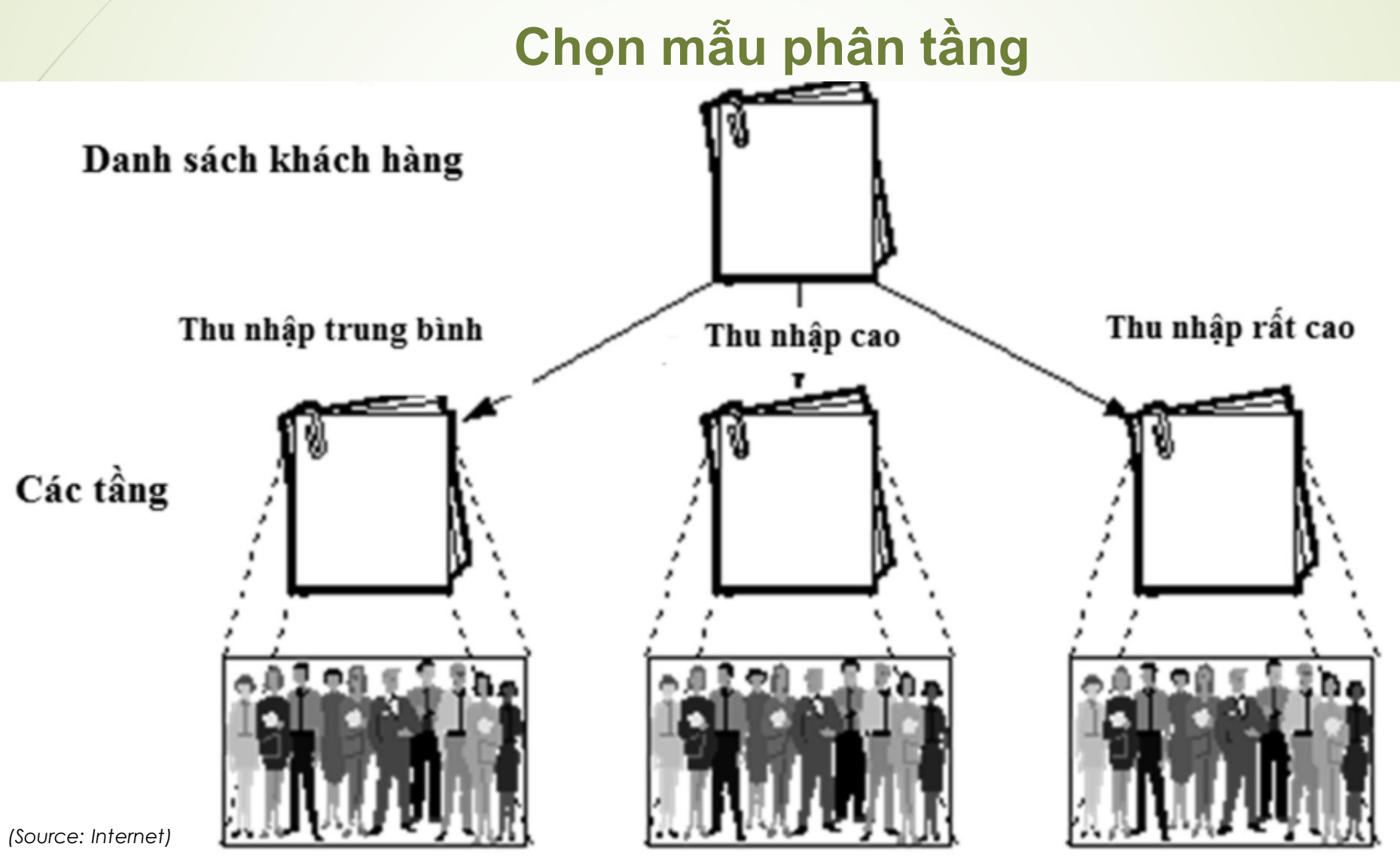




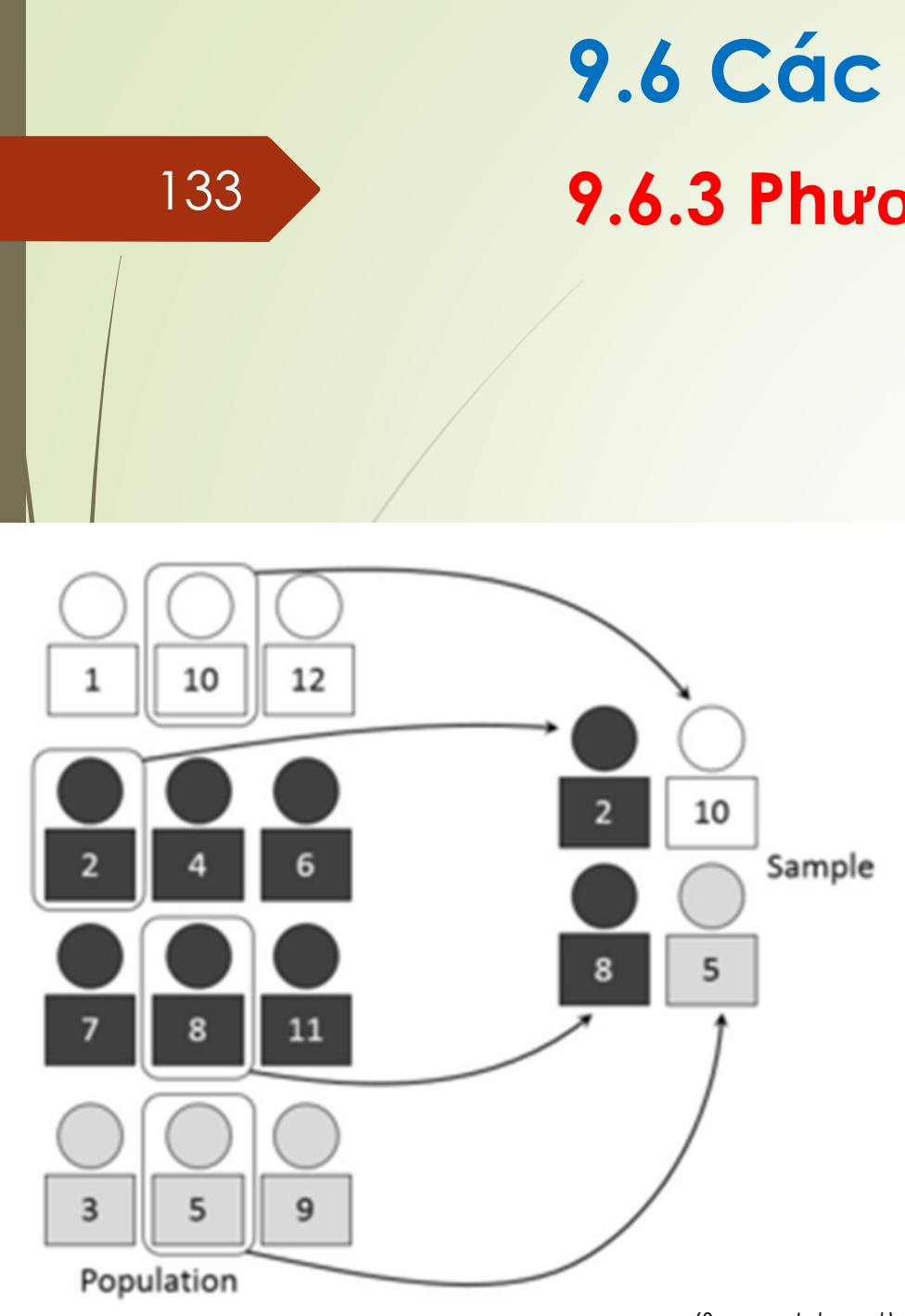

\subsection{Các phương pháp chọn mẫu}

\subsubsection{Phương pháp chọn mẫu xác suất \\ (Probability sampling)}

Chọn mẫu phân tầng (stratified sampling)

Ưu điểm:

- Đảm bảo mỗi nhóm đều có tính đại diện trong mẫu;

- Mỗi nhóm đều được thống kê và so sánh.

Nhược điểm:

- Yêu cầu thông tin chính xác về khung mẫu.

- Chi phí để có được danh sách mỗi tầng 


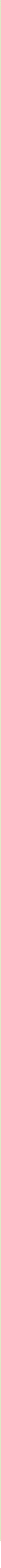




\subsection{Các phương pháp chọn mẫu}

\subsubsection{Sai lệch liên quan đến chọn mẫu}

$\checkmark$ Sai lệch do chọn mẫu (do tính đại diện của mẫu)

$\checkmark$ Sai lệch không do chọn mẫu (xảy ra trong quá trình phỏng vấn, hiệu chỉnh, nhập dữ liệu,..) 


\section{CÂU Hỏl}

Giống và khác giữa chọn mẫu phân tầng và chọn mẫu theo nhóm? 
9.7 Phương pháp xác định cỡ mẫu 


\subsection{Phương pháp xác định cỡ mẫu}

\subsubsection{Kích cỡ mẫu (sample size)}

Xác định cỡ mẫu (số đơn vị mẫu) chính là xác định số lượng đơn vị điều tra trong tổng thể mẫu để tiến hành thu thập số liệu. Yêu cầu của cỡ mẫu là vừa đủ để vừa đảm bảo độ tin cậy cần thiết của số liệu điều tra vừa đảm bảo phù hợp với điều kiện về nhân lực và kinh phí và có thể thực hiện được, tức là có tính khả thi. 


\subsection{Phương pháp xác định cỡ mẫu}

Có rất nhiều yếu tố ảnh hưởng đến việc xác định cỡ mẫu nghiên cứu như mục tiêu, nội dung, phạm vi nghiên cứu, phương pháp chọn mẫu,... Tuy nhiên, những yếu tố ảnh hưởng lớn nhất đến việc xác định cỡ mẫu là:

- Sự phong phú của tổng thể nghiên cứu: tổng thể nghiên cứu càng lớn, thường cần chọn mẫu càng lớn.

- Độ tin cậy muốn đạt được. Mẫu càng lớn thì độ tin cậy càng cao.

- Sai số cho phép 


\subsection{Phương pháp xác định cỡ mẫu}

> Sai số mẫu = sự khác biệt giữa tính chất của mẫu và tính chất của đám đông.

> Giảm sai số mẫu luôn là mục tiêu của bất kì kĩ thuật chọn mẫu nào.

$>$ Khi qui mô mẫu tăng, sai số mẫu sẽ giảm. 


\subsection{Phương pháp xác định cỡ mẫu}

\subsubsection{Mẫu lớn như thế nào?}

Mục tiêu là chọn mẫu tiêu biểu

$>$ Mẫu lớn luôn có tính tiêu biểu cao hơn.

$>$ Nhưng chọn mẫu lớn cũng tốn kém hơn.

> Và chọn mẫu lớn tức là phớt lờ sức mạnh của phương pháp chọn mẫu có khoa học 


\subsection{Phương pháp xác định cỡ mẫu}

A. Theo phương pháp chung:

- Không biết số lượng quần thể / số lượng quần thể chưa được cập nhật.

- Đã biết (chính xác / khoảng) số lượng quân thể

- Phương thức chọn mẫu ngẫu nhiên đơn giản

\section{B. Theo phương pháp xử lý}

- Phân tích nhân tố khám phá (exploratory factor analysis)

- Phân tích tương quan bội (multiple correlation) / hồi quy bội (multiple regression)

- Phân tích tương quan từng phần (partial correlation)

\section{Theo phần mềm G*Power}

Lưu ý: Cần phân biệt n (nhỏ) và N (in hoa) trong công thức. 


\subsection{Phương pháp xác định cỡ mẫu}

\section{A. Theo phương pháp chung}

Không biết số lượng quần thể / số lượng quần thể chưa được cập nhật.

Dùng công thức tính của Cochran's (1977) $)^{1}$

Trong đó:

$$
n=\frac{Z^{2}}{4 e^{2}}
$$

$\mathrm{n}=$ cõ mẫu

Z = khoảng tin cậy 95\%, tại giá trị 1.96

e = sai số cho phép (mức sai lầm) $(+-3 \%,+-4 \%,+-5 \% \ldots$..). 


\subsection{Phương pháp xác định cỡ mẫu}

\section{A. Theo phương pháp chung}

Đã biết (chính xác / khoảng) số lượng quần thể - Simplified formula for proportions

Dùng công thức tính của Yamane (1967)²

$$
n=\frac{N}{1+N e^{2}}
$$

Trong đó:

$\mathrm{n}=$ cõ mẫu

$\mathrm{N}=$ tổng quần thể

$\mathrm{e}=$ sai số cho phép (mức sai lầm) $(+-3 \%,+-4 \%,+-5 \% \ldots$..). 


\subsection{Phương pháp xác định cỡ mẫu}

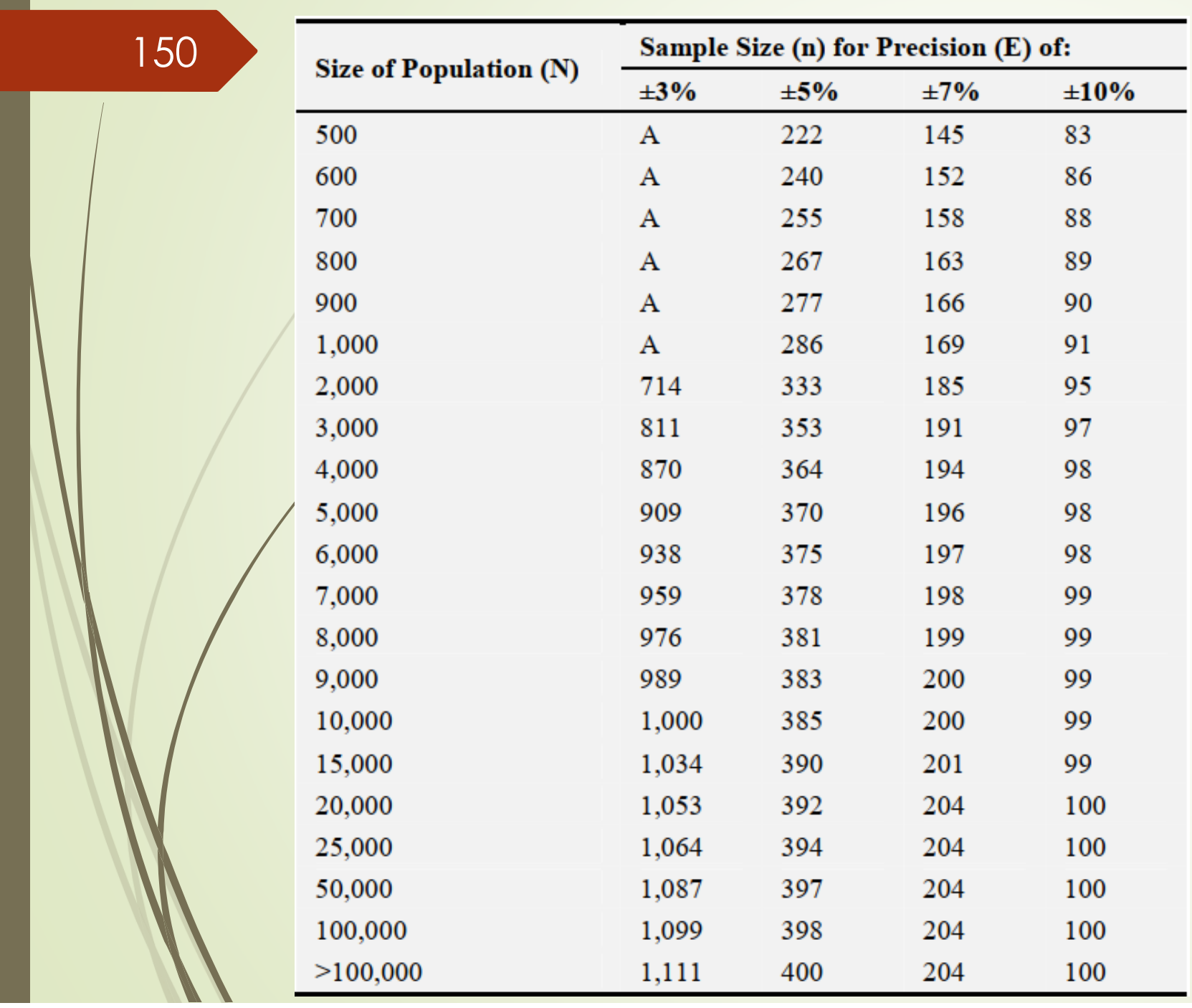

Ph.D. Đào Duy Tùng, TayDo Uni

(Source: Yamane, 1967) 


\subsection{Phương pháp xác định cỡ mẫu}

Table for Determining Sample Size from a Giten Population

\begin{tabular}{|c|c|c|c|c|c|}
\hline$N$ & $S$ & $N$ & $S$ & $N$ & $S$ \\
\hline 10 & 10 & 220 & 140 & 1200 & 291 \\
\hline 15 & 14 & 230 & 144 & 1300 & 297 \\
\hline 20 & 19 & 240 & 148 & 1400 & 302 \\
\hline 25 & 24 & 250 & 152 & 1500 & 306 \\
\hline 30 & 28 & 260 & 155 & 1600 & 310 \\
\hline 35 & 32 & 270 & 159 & 1700 & 313 \\
\hline 40 & 36 & 280 & 162 & 1800 & 317 \\
\hline 45 & 40 & 290 & 165 & 1900 & 320 \\
\hline 50 & 44 & 300 & 169 & 2000 & 322 \\
\hline 55 & 48 & 320 & 175 & 2200 & 327 \\
\hline 60 & 52 & 340 & 181 & 2400 & 331 \\
\hline 65 & 56 & 360 & 186 & 2600 & 335 \\
\hline 70 & 59 & 380 & 191 & 2800 & 338 \\
\hline 75 & 63 & 400 & 196 & 3000 & 341 \\
\hline 80 & 66 & 420 & 201 & 3500 & 346 \\
\hline 85 & 70 & 440 & 205 & 4000 & 351 \\
\hline 90 & 73 & 460 & 210 & 4500 & 354 \\
\hline 95 & 76 & 480 & 214 & 5000 & 357 \\
\hline 100 & 80 & $500^{\circ}$ & 217 & 6000 & 361 \\
\hline 110 & 86 & 550 & 226 & 7000 & 364 \\
\hline 120 & 92 & 600 & 234 & 8000 & 367 \\
\hline 130 & 97 & 650 & 242 & 9000 & 368 \\
\hline 140 & 103 & 700 & 248 & 10000 & 370 \\
\hline 150 & 108 & 750 & 254 & 15000 & 375 \\
\hline 160 & 113 & 800 & 260 & 20000 & 377 \\
\hline 170 & 118 & 850 & 265 & 30000 & 379 \\
\hline 180 & 123 & 900 & 269 & 40000 & 380 \\
\hline 190 & 127 & 950 & 274 & 50000 & 381 \\
\hline 200 & 132 & 1000 & 278 & 75000 & 382 \\
\hline 210 & 136 & 1100 & 285 & 1000000 & 384 \\
\hline
\end{tabular}

Note. $-N$ is population size.

$S$ is somple size.

\section{A. Theo phương pháp chung}

Đã biết (chính xác / khoảng) số lượng quần thể Simplified formula for proportions

Sử dụng bảng kích cõ mẫu của Krejcie and Morgan (1970)ํㅗำ

Lưu ý: Đây là công thức tính cỡ mẫu có kèm điều kiện. Điều kiện sẽ do người nghiên cứu tự đặt ra 


\subsection{Phương pháp xác định cỡ mẫu}

152

\section{B. Theo phương pháp xử lý}

Phân tích nhân tố khám phá (exploratory factor analysis)

Hair et al. $(2006,2009)^{4}$ chỉ ra mẫu tối thiểu $(=50)$, tốt hơn (=100), tỉ lệ quan sát:biến đo lường (5:1)

\section{$\mathrm{N}>\mathbf{5}^{*} \mathrm{~m}$}

Trong đó:

N: số lượng cõ mẫu

m: số lượng câu hỏi quan sát 


\subsection{Phương pháp xác định cỡ mẫu}

\section{B. Theo phương pháp xử lý}

Phân tích tương quan bội (multiple correlation)

Phân tích hồi quy bội (multiple regression)

Theo Tabachnick \& Fidell (2007) ${ }^{\frac{5}{}}$,

$$
\mathbf{N} \geq \mathbf{5 0}+\mathbf{8 m}
$$

Trong đó:

$\mathrm{N}$ : số lượng cỡ mẫu

m: số biến độc lập

Theo Stevens (1996)ำ tối thiểu 15 mẫu trên 1 biến độc lập 


\subsection{Phương pháp xác định cỡ mẫu}

B. Theo phương pháp xử lý

Phân tích tương quan từng phần (partial correlation)

Theo Harris $(1985,2013)^{6}$

$$
\mathbf{N} \geq 104+\mathbf{m}
$$

Trong đó:

$\mathrm{N}$ : cõ mẫu

m: số biến độc lập 


\subsection{Phương pháp xác định cỡ mẫu}

\section{5}

C. Theo phần mềm G*Power

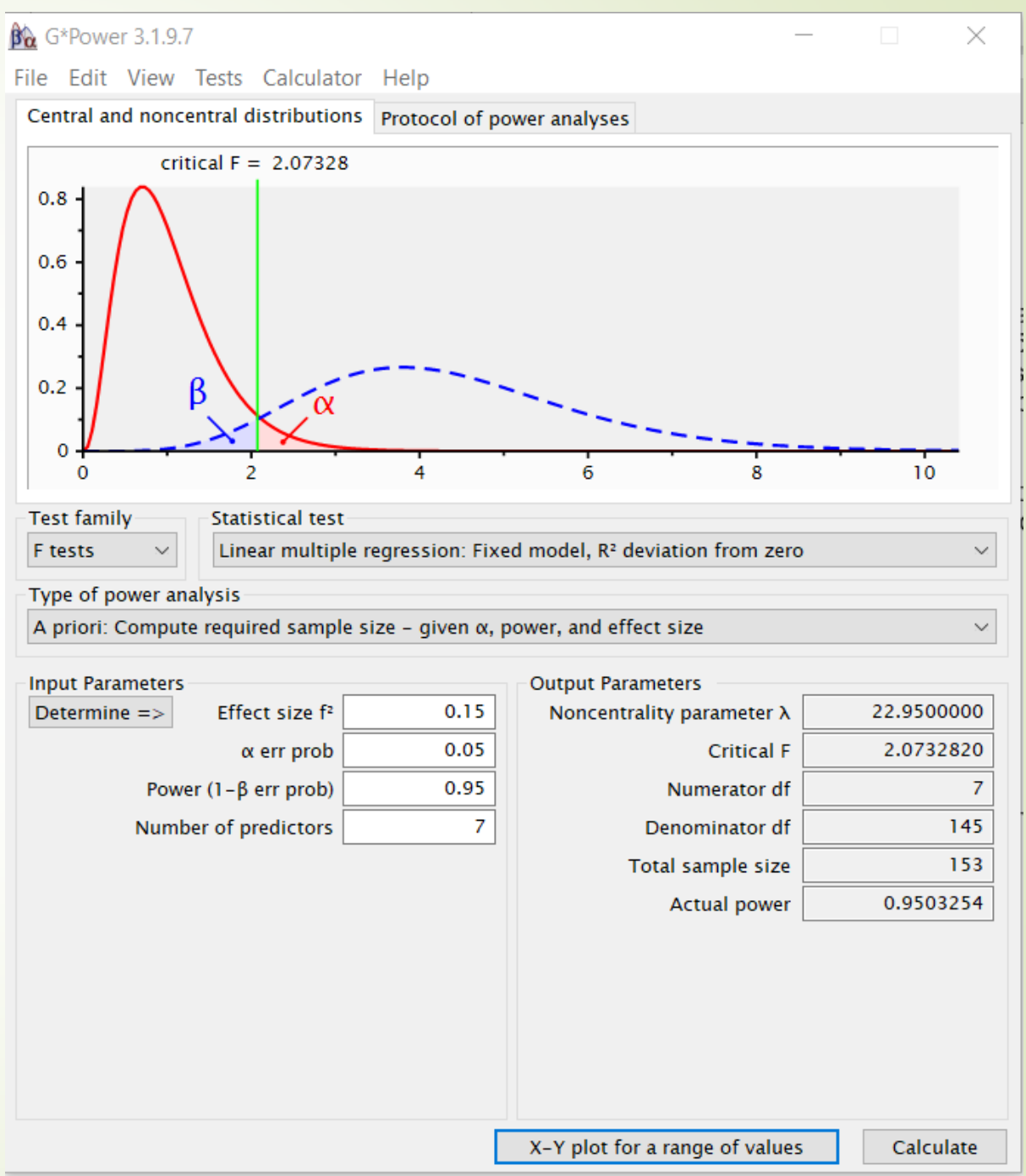




\section{Tài liệu tham khảo}

1. Babbie, E. R. (2015). The Practice of Social Research - Standalone Book (14th ed.). Cengage Learning.

2. Cochran, W. G. (1977). Sampling Techniques, 3rd Edition (3rd ed.). John Wiley \& Sons.

3. Harris, R. (1985). A Primer of Multivariate Statistics (2nd ed.). HBJ College \& School Division.

4. Harris, R. J. (2013). A Primer of Multivariate Statistics (3rd ed.). Psychology Press.

5. Jr, J. H. F., Black, W. C., Babin, B. J., \& Anderson, R. E. (2009). Multivariate Data Analysis (7th Edition) (7th ed.). Pearson.

6. Jr., J. H. F., Celsi, M., Money, A., \& Samouel, P. (2015). The Essentials of Business Research Methods (3rd ed.). Routledge.

7. Krejcie, R. V., \& Morgan, D. W. (1970). Determining Sample Size for Research Activities. Educational and Psychological Measurement, 30(3), 607-610. https://doi.org/10.1177/001316447003000308 


\section{Tài liệu tham khảo}

8. Tabachnick, B. G., \& Fidell, L. S. (2007). Using multivariate statistics (5th ed.). Allyn \& Bacon/Pearson Education

9. The Online Research Guide for your Dissertation and Thesis. (n.d.). Lærd Dissertation. Retrieved June 30, 2021, from https://dissertation.laerd.com/

10. Research Methods. (n.d.). Scribbr. Retrieved June 30, 2021, from https://www.scribbr.com/methodology/

11. Saunders, M. N. K., Lewis, P., \& Thornhill, A. (2015). Research Methods for Business Students (7th Edition) (7th ed.).

12. Statistics guides. A handbook for beginners in research | Sổ tay dành cho người mới bắt đầu nghiên cứu. https://statswork.wiki/

13. Sekaran, U., \& Bougie, R. (2016). Research Methods For Business: A Skill Building Approach (7th ed.). Wiley.

14. Stevens, J. (1996). Applied multivariate statistics for the social sciences (3rd ed.). Mahwah, NJ: Lawrence Erlbaum Associates, Publishers.

15. Survey Intelligence Blog. (n.d.). QuestionPro. Retrieved June 30, 2021, from https://www.questionpro.com/blog/

16. Yamane, T. (1967). Statistics An Introductory Analysis. 2nd Edition (Second Edition). Harper \& Row. 
Kết thúc chương 7 